\title{
¿Sospechar para igualar? Un análisis «estricto» de la doctrina de las categorías sospechosas a partir de la jurisprudencia del Tribunal Constitucional peruano y la Corte Interamericana de Derechos Humanos" To suspect in order to equate? A «strict» scrutiny of the suspect classifications doctrine from the case law of the Peruvian Constitutional Court and the Inter-American Court of Human Rights
}

\author{
TRILCE VALDIVIA AGUILAR** \\ Universidad Católica San Pablo (Perú)
}

Resumen: Este artículo es un estudio crítico, introductorio y valorativo de la doctrina de las categorías sospechosas de discriminación a partir de la jurisprudencia del Tribunal Constitucional del Perú y de la Corte Interamericana de Derechos Humanos. Su objetivo es describir las peculiaridades de dicha doctrina en la jurisprudencia de ambos tribunales y analizar críticamente su fundamentación, así como sus consecuencias: el examen de escrutinio estricto. Para cumplir con dicho propósito, se describen los casos en los que los tribunales se han referido explícitamente a la doctrina de las categorías sospechosas. A partir de ellos, la autora identifica que ambos tribunales han adoptado la noción de igualdad como reconocimiento de grupos vulnerables para fundamentar dicha doctrina y establecido como su principal efecto la aplicación de un examen estricto de proporcionalidad. Finalmente, el trabajo valora críticamente dichos hallazgos jurisprudenciales y propone algunas sugerencias para superar las objeciones presentadas.

Palabras clave: Categorías sospechosas, igualdad y no discriminación, escrutinio estricto, juicio de igualdad, Corte Interamericana de Derechos Humanos, Tribunal Constitucional Peruano

\footnotetext{
Abstract: This paper is an introductory study of the doctrine of suspect classifications based on the case law of the Peruvian Constitutional Court and the Inter-American Court of Human Rights. It aims to describe the special features of this doctrine as well as to critically analyze its proposed justification and the consequences of its application: The strict scrutiny test. To achieve this purpose, this work describes the case law in which both courts

* Una versión previa de este artículo se presentó como comunicación en la Mesa Temática № 5 de las III Jornadas Nacionales de Derechos Fundamentales, organizada por el área de Derecho Constitucional de la Pontificia Universidad Católica del Perú (PUCP) en octubre de 2018. La autora agradece los comentarios José Chávez-Fernández Postigo y de los árbitros que evaluaron este trabajo, los cuales fueron de gran ayuda para mejorar aspectos sustanciales y formales del mismo.

** Magíster en Derecho Internacional de los Derechos Humanos por la Northwestern University (Chicago, Illinois, EE. UU.). Docente titular de los cursos de Seminario de Introducción al Derecho Comparado y Derecho Constitucional en el Departamento de Derecho y Ciencia Política de la Universidad Católica San Pablo de Arequipa, Perú.

Código ORCID: 0000-0002-6842-1632. Correo electrónico: tvaldivia@ ucsp.edu.pe
} 
have explicitly mentioned this doctrine. Based on this study, the author identifies that the foundation of this doctrine lies in the notion of equality as recognition of vulnerable groups and that both tribunals have established as its main effect the application of a strict scrutiny test. Finally, the author critically assesses these jurisprudential findings.

Key words: Suspect classifications, equality and non-discrimination, strict scrutiny, equality test, Inter-American Court of Human Rights, Peruvian Constitutional Court

CONTENIDO: I. LAS CATEGORÍAS SOSPECHOSAS Y EL TC PERUANO.- II. LAS CATEGORÍAS SOSPECHOSAS Y EL TC PERUANO.- III. LAS CATEGORÍAS SOSPECHOSAS EN LA JURISPRUDENCIA DE LA CORTE IDH.- IV. UN ANÁLISIS ESTRICTO DE LAS "CATEGORÍAS SOSPECHOSAS».- IV.1. LA IGUALDAD DE GRUPO BAJO EXAMEN.- IV.2. EL ESCRUTINIO ESTRICTO BAJO SOSPECHA.V. CONCLUSIÓN.

\section{INTRODUCCIÓN}

El creciente diálogo entre tribunales constitucionales, cortes supremas y tribunales internacionales de derechos humanos posibilita la migración de una serie de conceptos y aproximaciones a los derechos fundamentales. En ese marco, el principio de no discriminación se ha visto sujeto a renovados esfuerzos jurisprudenciales por actualizar su contenido de modo que su eficacia como herramienta para el develamiento de diferenciaciones injustas no se vea mermada. Uno de estos esfuerzos fue la creación de la doctrina de las «categorías sospechosas de discriminación» en el seno de la Corte Suprema de los Estados Unidos, la que plantea la existencia de ciertos criterios vedados para la diferenciación legislativa, de modo que cualquier distinción basada en ellas suponga la evaluación de la medida bajo un escrutinio «estricto». Esta idea ha migrado al constitucionalismo latinoamericano $^{1}$ y ha sido adoptada tanto por el Tribunal Constitucional del Perú (en adelante, TC) como por la Corte Interamericana de Derechos Humanos (en adelante, Corte IDH).

Este trabajo es un estudio introductorio a la doctrina de las categorías sospechosas de discriminación en la jurisprudencia del TC y de la Corte IDH. Su objetivo es describir las peculiaridades de dicha doctrina

1 Además de los tribunales que son objeto de estudio en este trabajo, dicha doctrina ha sido adoptada, entre otras instancias de justicia, por la Corte Suprema de Justicia de México (véase Controversia Constitucional 32/2009, 2009; Amparo Directo en Revisión 1387/2012, 2012; Acción de Inconstitucionalidad 8/2014, 2015; y Amparo en Revisión 615/2013, 2013, entre otros), la Corte Suprema de Justicia de la Nación Argentina (véase Hooft, Pedro Cornelio Federico vs. Buenos Aires, Provincia de s/ acción declarativa de inconstitucionalidad, 2004), la Corte Constitucional de Colombia (véase Sentencia C-093, 2001; C-671, 2001; y T-376, 2013, entre otras) y la Corte Constitucional de Ecuador (véase Sentencia Nº 080-13-SEP-CC, 2013; Sentencia N 292-16-SEP-CC, 2016; Sentencia $\mathrm{N}^{\circ}$ 057-17-SEP-CC, 2017; y Sentencia Nº04-18-SEP-CC, 2018). Asimismo, desde la doctrina, se ha analizado este concepto en la jurisprudencia del Tribunal Constitucional de Chile; al respecto, véase Díaz de Valdés (2018). 
en la jurisprudencia de ambos tribunales y analizar críticamente los fundamentos, así como los efectos de su aplicación: el examen de escrutinio estricto. El trabajo se divide en tres acápites: el primero desarrolla la doctrina de las categorías sospechosas en la jurisprudencia del TC, el segundo hace lo propio respecto de la jurisprudencia de la Corte IDH, y el tercero valora críticamente tanto la justificación como los efectos de la aplicación de dicha doctrina.

\section{II.LAS CATEGORÍAS SOSPECHOSAS Y ELTC PERUANO}

Son categorías sospechosas aquellos criterios sobre los cuales no pueden efectuarse distinciones entre los individuos; es decir, se presume su inconstitucionalidad por existir un alto grado de probabilidad de discriminación injusta sobre su base. La doctrina se origina en el seno de la Corte Suprema norteamericana a fin de proteger a minorías raciales (Baker, 2008, p. 877). Es a partir de su interpretación del artículo 2.2 de la Constitución Política del Perú que el TC ha incorporado la doctrina de las categorías sospechosas de discriminación en su jurisprudencia. Esta disposición contiene dos cláusulas: una primera, que reconoce el derecho a la igualdad ante la ley; y otra, que reconoce el derecho a no ser discriminado por motivos tales como «el origen, raza, sexo, idioma, religión, opinión, condición económica o de cualquier otra índole». La primera cláusula reconoce el derecho-principio de igualdad en sus dos vertientes, igualdad en la ley e igualdad en la aplicación de la ley; mientras que la segunda reconoce el derecho a la no discriminación, el que encuentra directa conexión con la doctrina de las categorías sospechosas toda vez que, en sentido estricto, el principio de no discriminación prohíbe todas aquellas distinciones entre personas que impliquen una negación de la dignidad humana por fundarse en la superioridad o inferioridad del valor intrínseco de un grupo de personas respecto de otras (Bilbao Ubillús \& Rey Martínez, 2003, p. 111; Fernández, 2003, p. 81).

Las diferentes constituciones y tratados de derechos humanos reconocen múltiples criterios prima facie prohibidos de discriminación. No se acepta de forma unánime que todos los criterios listados sean igualmente sospechosos; en otras palabras, un sector de la doctrina reconoce una jerarquía de criterios prohibidos, siendo sospechosos solo algunos de ellos (Bayefsky, 1990; Pérez Portilla, 2005). Las cláusulas de no discriminación son por lo general fórmulas abiertas que permiten su actualización por parte de los tribunales. La pregunta central es cuál es el criterio utilizado por los tribunales para incorporar nuevas categorías sospechosas, cuestión que intentaremos responder en el contexto del TC peruano. No obstante, puede observarse en el derecho internacional de los derechos humanos y en el derecho constitucional

¿SOSPECHAR

PARA IGUALAR?

UN ANÁLISIS

«ESTRICTO»DE

LA DOCTRINA DE

LAS CATEGORÍAS

SOSPECHOSAS

A PARTIR DE LA

JURISPRUDENCIA

DEL TRIBUNAL

CONSTITUCIONAL

PERUANO

Y LA CORTE

INTERAMERICANA

DE DERECHOS

HUMANOS

TO SUSPECT

IN ORDER

TO EQUATE?

$A$ «STRICT»

SCRUTINY OF

THE SUSPECT

CLASSIFICATIONS

DOCTRINE FROM

THE CASE LAW OF

THE PERUVIAN

CONSTITUTIONAL

COURT AND THE

INTER-AMERICAN

COURT OF HUMAN

RIGHTS 
comparado que muchas veces estos criterios obedecen a características personales inmutables (en el sentido de que modificarlas implicaría afectar severamente la identidad personal), características personales irrelevantes como criterios de reparto, características cuya distinción impacta gravemente sobre la dignidad humana, así como a grupos sociales vulnerables o minorías históricamente marginadas (Gerards, 2013, pp. 113-114).

La doctrina señala que, en muchas ocasiones, las distinciones sobre la base de categorías sospechosas se fundan en prejuicios, juicios incorrectos sobre la menor valía de un grupo de personas, estereotipos de tipo irracional, simplificaciones de la realidad basadas en errores o generalizaciones exageradas que sirven como indicios para atribuir a una persona roles o rasgos en razón de su pertenencia a cierto grupo social o de la posesión de cierta característica personal. Se trata, pues, de ideologías fundadas sobre «modelos a seguir» imposibles de sostenerse racionalmente, aversiones y preferencias personales de tipo superficial (es decir, aquellas abrazadas por sujetos desinformados o irracionales que producen daños innecesarios a otros) (Alexander, 1992, p. 219).

En la sentencia del caso Miguel Alejandro Cadillo Palomino vs. Ministerio de Trabajo y Promoción del Empleo, el TC peruano mencionó por primera vez en su jurisprudencia la llamada doctrina de las «categorías sospechosas de discriminación». Dicho fallo fue expedido en el marco de un proceso de amparo en el que el recurrente, Miguel Cadillo, reclamaba haber sido injustamente excluido del Registro Nacional de Trabajadores Cesados Irregularmente. Este alegó que, a pesar de cumplir con los mismos requisitos de otros trabajadores cesados, había sido excluido del registro sin una justificación objetiva y razonable, lo que ocasionó que no sea reincorporado en su puesto de trabajo. Si bien el señor Cadillo arguyó que en su caso debía aplicarse el «principio de analogía», reconocido en el artículo 3 de la ley $\mathrm{N}^{\circ} 29059$, la carta en la que se le comunica que la Administración decidió excluirlo del Registro Nacional de Trabajadores Cesados Irregularmente no ofrecía ningún elemento que justificase la no aplicación de este principio (2010, § 6). El TC calificó la situación del señor Cadillo como una de discriminación indirecta, agravada en razón a su condición de discapacidad, la cual el TC considera un criterio sospechoso o potencialmente discriminatorio, por lo que debe reputarse prima facie como inconstitucional (2010, § 34). iCómo define nuestro Alto Tribunal a los criterios sospechosos? A juicio del TC, son categorías sospechosas:

Aquellos criterios de clasificación que aluden a determinados grupos sociales que han sido históricamente discriminados y que, por ende, merecen recibir una tutela especial o diferenciada de parte del ordenamiento jurídico. En este caso, dicha protección cualificada 
consiste en establecer que toda distinción que se funde en alguno de estos criterios expresamente vedados, estará afecta a una presunción de inconstitucionalidad, la cual solo podrá ser desvirtuada a través de una justificación estricta, objetiva y razonable (§ 32).

En una sentencia ulterior, el TC reconoció además que la discriminación basada en un criterio sospechoso, como la discapacidad, no solo se produce cuando se realiza un trato diferenciado injustificado, sino también cuando «frente a situaciones sustancialmente desiguales se brinda un trato igualitario» (Jane Margarita Cósar Camacho y otros vs. Supermercados Peruanos S.A. Plaza Vea, 2014, § 6). En esa línea, el TC aludió a la obligación estatal de especial protección de las personas con discapacidad reconocida en los artículos 2.2 y 7 de la Constitución, e interpretó a partir de ella «el deber estatal de establecer ajustes razonables orientados a promover las condiciones necesarias que permitan eliminar las exclusiones de las que históricamente han sido víctimas» (§ 7). Como puede apreciarse, en estos casos, el criterio sospechoso no actúa como escudo frente a la diferenciación injustificada, requiriendo evaluar la medida diferenciadora desde un escrutinio estricto; sino como arma para justificar la erradicación de las causas de la marginación histórica de una población vulnerable. En ese sentido, el TC notó que

La falta de ambientes físicos adecuados a las necesidades de las personas con discapacidad ha desencadenado, primero, su marginación y, luego, su exclusión de todos estos procesos sociales, presentándose tales déficits de organización de la estructura social como el principal impedimento para que este sector de la población acceda al goce y ejercicio pleno de sus derechos y libertades $(\S 9)$.

Para el TC, el hecho de que estos criterios sospechosos no se encuentren listados en el artículo 2.2 de la Constitución no es óbice para su reconocimiento, toda vez que dicha cláusula no tiene caracter de numerus clausus. Además del origen, la raza, el sexo, la religión, la opinión, la condición económica, la expresión «de cualquier otra índole» del artículo 2.2 de la Carta Magna es, a juicio del TC, «una fórmula adoptada por el constituyente que permite actualizar el contenido de la Constitución frente al surgimiento de nuevas situaciones de vulnerabilidad» (María Chura Arcata us. Banco de la Nación, 2017, § 19). En esa línea, además de la discapacidad, el TC ha identificado como nueva categoría sospechosa a la «edad». En sentido similar a fallos anteriores, el TC puntualizó que «cualquier distinción tomando en cuenta este factor requerirá de una fuerte argumentativa de parte del órgano que efectuó el trato diferenciado a fin de justificar la constitucionalidad de la medida adoptada, la cual será sometida a escrutinio estricto» (§ 31).

¿SOSPECHAR

PARA IGUALAR?

UN ANÁLISIS

«ESTRICTO» DE

LA DOCTRINA DE

LAS CATEGORÍAS

SOSPECHOSAS

a PARTIR DE LA

JURISPRUDENCIA

DEL TRIBUNAL

CONSTITUCIONAL

PERUANO

Y LA CORTE

INTERAMERICANA

DE DERECHOS

HUMANOS

TO SUSPECT

IN ORDER

TO EQUATE?

$A$ «STRICT»

SCRUTINY OF

THE SUSPECT

CLASSIFICATIONS

DOCTRINE FROM

THE CASE LAW OF

THE PERUVIAN

CONSTITUTIONAL

COURT AND THE

INTER-AMERICAN

COURT OF HUMAN

RIGHTS 
En la argumentación de esta sentencia resulta ilustrativo reparar en la metodología del TC para identificar a nuevos criterios sospechosos de discriminación injusta. A juicio del TC, para la identificación de un nuevo criterio sospechoso, no parece necesario probar o justificar su razonabilidad o irrazonabilidad como criterio de reparto. Como es sabido, la edad es un criterio común de diferenciación — por ejemplo, el criterio de mayoría de edad opera como título habilitante de una serie de derechos civiles-, por lo que no parecería conveniente calificar a la «edad» como criterio prima facie prohibido de discriminación (Massachussets Board of Retirement v. Murgia; y Gregory v. Aschroft, 1976). No obstante, el TC reconoce a la «edad» como criterio prohibido de discriminación cuando este sirve para proteger a un grupo vulnerable, como son las personas adultas mayores o de la tercera edad. Consecuentemente, en opinión del TC, la edad no sería un criterio prohibido de discriminación en sí mismo, sino en función del grupo social que protege. ¿Cómo decide el TC qué grupos sociales han de ser protegidos por las categorías sospechosas? De la argumentación de la sentencia analizada, pareciera que para el TC la metodología principal para proteger especialmente a un grupo social contra situaciones de discriminación consiste en identificar cuán arraigada socialmente se encuentra su situación de vulnerabilidad en las circunstancias actuales ${ }^{2}$. Asimismo, a partir de la ratio decidendi del TC, parece identificarse una correlación entre categoría sospechosa y deber especial de protección, convirtiéndose a los integrantes de grupos vulnerables en «titulares superreforzados de derechos fundamentales» o «titulares con una calidad especial» (María Chura Arcata vs. Banco de la Nación, 2017, § 25). La línea argumentativa antes descrita no solo ha sido aplicada por el TC para referirse a la identificación de nuevos criterios sospechosos; así, por ejemplo, cuando se ha pronunciado sobre la prohibición de discriminación por sexo, ha enfatizado que esta tiene como propósito terminar «con la histórica situación de inferioridad de la mujer en la vida social, cultural, económica y política» (Andrea Celeste Álvarez Villanueva vs. Ministerio de Defensa, 2015, § 22).

Adicionalmente, conviene reparar en la metodología adoptada por el TC para juzgar una diferenciación basada en una categoría sospechosa. El TC ha señalado que para casos que involucren una diferenciación basada en un criterio sospechoso, el juez constitucional habrá de sujetarse a las siguientes reglas (véase María Chura Arcata vs. Banco de la

2 Así, por ejemplo, el TC cita al Comité de Derechos Económicos, Sociales y Culturales, órgano de vigilancia del Pacto Internacional de Derechos Económicos, Sociales y Culturales de las Naciones Unidas, cuando afirma que: «[n]i en el Pacto ni en la Declaración Universal de Derechos Humanos se hace explícitamente referencia a la edad como uno de los factores prohibidos. En vez de considerar que se trata de una exclusión intencional, esta omisión se explica probablemente por el hecho de que, cuando se adoptaron estos instrumentos, el problema del envejecimiento de la población no era tan evidente o tan urgente como en la actualidad» (Observación General N ${ }^{\circ} 6$ sobre los derechos económicos, sociales y culturales de las personas mayores, U.N. Doc. E/C.12/1995/16/ Rev.l, 1995, § 11). 
Nación, 2017, § 34; Fiscal de la Nación vs. Congreso de la República, 2006, $\S \S 128-151$; Colegio de Abogados del Cono Norte de Lima vs. Congreso de la República, 2005, §§ 35-41; y Miguel Alejandro Cadillo Palomino vs. Ministerio de Trabajo y Promoción del Empleo, 2010, § 53).

\section{Primer paso - verificación de la diferenciación legislativa}

En este primer nivel, se contrasta el supuesto de hecho aparentemente discriminatorio con el supuesto fáctico que sirve como término de comparación. Para el TC, «en el juicio de igualdad, ese objeto, sujeto, situación o relación con el cual se realiza el contraste, se denomina término de comparación (tertium comparationis)» (Miguel Alejandro Cadillo Palomino vs. Ministerio de Trabajo y Promoción del Empleo, 2010, $\S 53)$. Para que este tertium comparationis sea válido debe tratarse, en primer lugar, de un supuesto de hecho lícito y, en segundo lugar, «debe ostentar propiedades que, desde un punto de vista fáctico y jurídico resulten sustancialmente análogas a las que ostenta la situación jurídica que se reputa como discriminatoria» ( $(54)$.

2. Segundo paso - determinación del nivel de intensidad de la intervención en la igualdad

- Intensidad grave, «cuando la discriminación se sustenta en alguno de los motivos prohibidos por la Constitución (artículo 2, inciso 2: origen, raza, sexo, idioma, religión, opinión, condición económica) y, además, tiene como consecuencia el impedimento del ejercicio o goce de un derecho fundamental o constitucional» (Colegio de Abogados del Cono Norte de Lima vs. Congreso de la República, 2005, § 35); o aunque, sin tratarse de un derecho fundamental, se trata de uno que permite la «realización de otros derechos y principios reconocidos en la Constitución» (María Chura Arcata vs. Banco de la Nación, 2017, § 37).

- Intensidad media, «cuando la discriminación se sustenta en alguno de los motivos prohibidos por la propia Constitución (artículo 2, inciso 2: origen, raza, sexo, idioma, religión, opinión, condición económica) y, además, tiene como consecuencia el impedimento del ejercicio o goce de un derecho de rango meramente legal o el de un interés legítimo» (Colegio de Abogados del Cono Norte de Lima vs. Congreso de la República, 2005, § 35).

- Intensidad leve, «cuando la discriminación se sustenta en motivos distintos a los proscritos por la propia Constitución y, además, tiene como consecuencia el impedimento del ejercicio o goce de un derecho de rango meramente legal o el de un interés legítimo» (Colegio de Abogados del Cono Norte de Lima vs. Congreso de la República, 2005, §35).

¿SOSPECHAR

PARA IGUALAR?

UN ANÁLISIS

«ESTRICTO» DE

LA DOCTRINA DE

LAS CATEGORÍAS

SOSPECHOSAS

A PARTIR DE LA

JURISPRUDENCIA

DEL TRIBUNAL

CONSTITUCIONAL

PERUANO

Y LA CORTE

INTERAMERICANA

DE DERECHOS

HUMANOS

TO SUSPECT

IN ORDER

TO EQUATE?

$A$ «STRICT»

SCRUTINY OF

THE SUSPECT

CLASSIFICATIONS

DOCTRINE FROM

THE CASE LAW OF

THE PERUVIAN

CONSTITUTIONAL

COURT AND THE

INTER-AMERICAN

COURT OF HUMAN

RIGHTS 
3. Tercer paso - finalidad constitucional de la medida diferenciadora

El TC analiza «si la intervención tiene un propósito de relevancia constitucional, o que al menos no se encuentra proscrito de manera directa por la Constitución». En este hito del examen de igualdad se determina «el estado de cosas o situación jurídica que el legislador pretende conformar a través del medio (objetivo), como identificar el bien jurídico cuyo fomento u optimización se intenta alcanzar (finalidad en sentido estricto)» (María Chura Arcata vs. Banco de la Nación, 2017, § 61). Cuando se trata de un examen de intensidad «grave» o «escrutinio estricto», la carga de la prueba se invierte y «será deber del demandado, y no del demandante, probar que dicha discriminación no se ha producido» (Miguel Alejandro Cadillo Palomino vs. Ministerio de Trabajo y Promoción del Empleo, 2010, § 34); asimismo, el demandado deberá demostrar la «imperiosa necesidad» de la medida diferenciadora (§ 34).

4. Cuarto paso - examen de idoneidad de la medida diferenciadora

En esta etapa el juez evalúa si existe una relación de causalidad entre «el medio adoptado a través de la intervención legislativa y el fin propuesto por el legislador» (Miguel Alejandro Cadillo Palomino vs. Ministerio de Trabajo y Promoción del Empleo, 2010, § 38). El TC sugiere realizar un análisis dividido en dos fases: «primero, establecer si existe una relación causal entre la intervención en la igualdad - medio - y el objetivo que se quiere conseguir o lograr; y, segundo, encontrar si hay relación entre el objetivo y la finalidad de la intervención» (María Chura Arcata vs. Banco de la Nación, 2017, § 65).

5. Quinto paso - examen de necesidad de la medida diferenciadora Aquí se evalúa que la medida legislativa aparentemente discriminatoria sea la que menos afecte tanto el derecho a la igualdad como otros derechos involucrados. En ese sentido, «debe determinarse (i) si es que no existen medios alternativos que sean, por lo menos, igualmente idóneos que el medio efectivamente adoptado; y además, si es que (ii) dentro de los medios alternativos por lo menos igualmente idóneos no existen algunos que sean más benignos con el derecho involucrado que el medio efectivamente adoptado» (María Chura Arcata vs. Banco de la Nación, 2017, § 75). En otras palabras, la medida debe reputarse indispensable.

6. Sexto paso - examen de proporcionalidad en sentido estricto Consiste en verificar que las ventajas obtenidas por la medida aparentemente discriminatoria sean proporcionales a la intervención en el derecho a la igualdad y en los otros derechos involucrados en el caso. Cuando se trata de un examen estricto, la duda sobre el nivel de 
«sacrificio» de un derecho fundamental favorece al demandante, lo que significaría decantarse por declarar la inconstitucionalidad de la ley.

\section{IIILAS CATEGORÍAS SOSPECHOSAS EN LA} JURISPRUDENCIA DE LA CORTE IDH

¿SOSPECHAR

PARA IGUALAR?

En la Convención Americana de Derechos Humanos (CADH) encontramos tres tipos de cláusulas de igualdad. De una parte, el artículo 1.1, considerado como cláusula subordinada, por lo que «forma parte integral de todos y cada uno de los artículos convencionales que establecen derechos y libertades» (Ruiz Chiriboga, 2012, p. 217). De otra parte, el artículo 24, que se considera una cláusula autónoma y tiene un mayor alcance pues se extiende a aquellos derechos reconocidos a nivel interno. Por último, hay una serie de cláusulas incorporadas a distintos artículos de la Convención, tales como los artículos 8.2 y 13.5 de la CADH. En la sentencia del caso Apitz Barbera y otros vs. Venezuela, la Corte IDH señaló enfáticamente que «si un Estado discrimina en el respeto o garantía de un derecho convencional, violaría el artículo 1.1 y el derecho sustantivo en cuestión. Si por el contrario la discriminación se refiere a una protección desigual de la ley interna, violaría el artículo 24» (2008, § 54). Analizando el sentido de las cláusulas subordinada y autónoma, González y Parra han afirmado que el artículo 1.1 recogería una concepción de discriminación destinada principalmente a la protección de grupos sociales vulnerables o discriminación como no sometimiento, y el artículo 24 una concepción de igualdad como no arbitrariedad (2008, p. 132). Ruiz Chiriboga es de opinión distinta y afirma que no existen propiamente dos cláusulas distintas, sino que el principio de igualdad y el de no discriminación son las dos caras de una misma moneda, toda vez que el principio de igualdad no prohíbe las diferencias razonables. De este modo, el artículo 24 contiene una prohibición de discriminación y el artículo 1.1 reconoce también el principio de igualdad ante la ley, influyendo ambos en su interpretación (2012, pp. 197-199). A continuación, pasaremos a dar detalle de lo que ha manifestado la Corte IDH al respecto en su jurisprudencia.

Sobre las categorías sospechosas, la Corte IDH se pronunció por primera vez en la sentencia del caso Atala Riffo y niñas vs. Chile (2012), en el que decidió si el Estado chileno había cometido un trato discriminatorio contra la señora Atala, en razón de su orientación sexual, durante el proceso de custodia de sus hijas. En este fallo, la Corte de San José señaló que «al interpretar la expresión "cualquier otra condición social" del artículo 1.1 de la Convención, debe siempre elegirse la alternativa más favorable al ser humano» (\$ 84). Por lo que, luego de realizado un ejercicio de interpretación evolutiva — que se fundamenta, sobre todo, en documentos de derecho indicativo o soft law (notas al pie 97-113

UN ANÁLISIS «ESTRICTO» DE LA DOCTRINA DE LAS CATEGoRÍas SOSPECHOSAS A PARTIR DE LA JURISPRUDENCIA DEL TRIBUNAL CONSTITUCIONAL PERUANO Y LA CORTE INTERAMERICANA DE DERECHOS HUMANOS

TO SUSPECT

IN ORDER

TO EQUATE?

$A$ «STRICT»

SCRUTINY OF

THE SUSPECT

CLASSIFICATIONS

DOCTRINE FROM

THE CASE LAW OF THE PERUVIAN

CONSTITUTIONAL COURT AND THE INTER-AMERICAN COURT OF HUMAN RIGHTS 
del fallo) ${ }^{3}$ - de la Convención Americana de Derechos Humanos, el Alto Tribunal Interamericano concluye que «la orientación sexual y la identidad de género de las personas son categorías protegidas por la Convención» (§§ 91-92). Para la Corte IDH, las minorías sexuales han sido víctimas de una situación de discriminación histórica y estructural (nota al pie 114), por lo que la posible falta de consenso sobre el respeto pleno a estas minorías no debería ser considerada como un «argumento válido para negarles o restringirles sus derechos humanos» (nota al pie 114). Asimismo, en relación con el examen de razonabilidad al que se deben someter las diferenciaciones que utilicen criterios prohibidos, la Corte IDH determinó que el mismo exigirá una «fundamentación rigurosa y de mucho peso, invirtiéndose, además, la carga de la prueba, lo que significa que corresponde a la autoridad demostrar que su decisión no tenía un propósito ni un efecto discriminatorio» (nota al pie 124).

El segundo caso en el que la Corte IDH ha tratado la doctrina de las categorías sospechosas es el de Norín Catrimán y otros vs. Chile (2014), en el que condenó al Estado chileno por violaciones de los derechos humanos, al debido proceso y a la igualdad y no discriminación cometidas contra integrantes del pueblo mapuche. Estas se habrían materializado en la dación de un número de sentencias entre los años 2013 y 2014 que justificaron su parte decisoria en las disposiciones de la ley 18.314 , la cual determina las conductas terroristas y fija su penalidad. La Corte sentenció que el Estado chileno había violado el derecho a un juez imparcial, toda vez que en las sentencias condenatorias de las presuntas víctimas se emplearon estereotipos y prejuicios negativos que asociaron a las comunidades mapuches con grupos terroristas. En su fallo, la Corte IDH reconoció el origen étnico como criterio prohibido de discriminación, extendiendo nuevamente el catálogo del artículo 1.1 de la CADH. Para justificar su decisión, la Corte IDH acudió a diversos tratados internacionales que prohíben explícitamente la discriminación por origen étnico (§ 202). Adicionalmente, recurrió a sendos instrumentos internacionales que reafirman el derecho de los pueblos indígenas a la no discriminación (§ 203). Sirva destacar que en este fallo la Corte IDH indicó haber interpretado la CADH sobre la base de las garantías del artículo 29 y de la Convención de Viena sobre el Derecho de los Tratados. Para la Corte IDH, al interpretar el contenido de la frase «cualquier otra condición social» del artículo 1.1 de la $\mathrm{CADH}$, debe «elegirse la alternativa más favorable para la tutela de los derechos protegidos por dicho tratado, según el principio de la norma más favorable al ser humano» (§ 203).

Posteriormente, en la sentencia del caso Granier y otros vs. Venezuela (2015), la Corte IDH interpretó que la categoría prohibida «opiniones

3 Al respecto, véase Ruiz Chiriboga (2012). 
políticas» protegería implícitamente la línea editorial de un canal de televisión, al ser esta «reflejo de las opiniones políticas de sus directivos y trabajadores en la medida en que estos involucren y determinen el contenido de la información transmitida» (\$ 224). La Corte IDH resaltó que, al tratarse el caso de una presunta discriminación en función de un criterio prohibido por el artículo 1.1 de la $\mathrm{CADH}$, «exige una fundamentación rigurosa y de mucho peso, invirtiéndose, además, la carga de la prueba, lo que significa que corresponde a la autoridad demostrar que su decisión no tenía un propósito ni un efecto discriminatorio» $(\$ 228)$.

Más adelante, en la sentencia del caso González Lluy y otros vs. Ecuador (2015), la Corte IDH incorporó al catálogo de criterios prohibidos de discriminación la condición de persona con VIH. Asimismo, la Corte IDH precisó que cada vez que se juzgue una diferenciación basada en un criterio sospechoso, esta debe ser evaluada bajo un escrutinio judicial más estricto, enmarcado en el principio de proporcionalidad (\$ 257) . Dicho examen estricto implica que la diferenciación debió buscar el logro de una finalidad imperiosa, y que haber recurrido a esa diferenciación era «el único método para alcanzar esa necesidad imperiosa» (\$ 256). La Corte IDH fue enfática al señalar que «las razones utilizadas por el Estado para realizar la diferenciación de trato deben ser particularmente serias y estar sustentadas en una argumentación exhaustiva» (§ 256), además de corresponderle a la autoridad la carga de la prueba; es decir, la demostración de que la medida no tenía un propósito discriminatorio. Para justificar la incorporación de este criterio, la Corte IDH recurrió a las interpretaciones que han realizado el Comité de Derechos Económicos, Sociales y Culturales y el Comité de Derechos del Niño, los que han calificado al «estado de salud» como criterio prohibido de discriminación. La Corte encontró que Thalía y su familia habían sido víctimas del estigma social asociado a su condición de personas con VIH, lo que generó la expulsión de su centro educativo y la imposibilidad de un ejercicio adecuado de su derecho a la educación. De igual manera, la Corte IDH encontró que la discriminación de la que fue objeto Thalía González Lluy tuvo un alcance mayor que el de una discriminación genérica, basada en un criterio sospechoso. Para la Corte IDH, en este caso se produjo una situación de discriminación interseccional, en la que confluyeron

[...] múltiples factores de vulnerabilidad y riesgo de discriminación asociados a su condición de niña, mujer, persona en situación de pobreza y persona con VIH. La discriminación que vivió Talía no sólo fue ocasionada por múltiples factores, sino que derivó en una forma

4 Este principio ha sido desarrollado en jurisprudencia previa por la Corte IDH, por ejemplo, en Kimel vs. Argentina (2008, §§ 70-84).

¿SOSPECHAR

PARA IGUALAR?

UN ANÁLISIS

«ESTRICTO» DE

LA DOCTRINA DE

LAS CATEGORÍAS

SOSPECHOSAS

A PARTIR DE LA

JURISPRUDENCIA

DEL TRIBUNAL

CONSTITUCIONAL

PERUANO

Y LA CORTE

INTERAMERICANA

DE DERECHOS

HUMANOS

TO SUSPECT

IN ORDER

TO EQUATE?

$A$ «STRICT»

SCRUTINY OF

THE SUSPECT

CLASSIFICATIONS

DOCTRINE FROM

THE CASE LAW OF

THE PERUVIAN

CONSTITUTIONAL

COURT AND THE

INTER-AMERICAN

COURT OF HUMAN

RIGHTS 
específica de discriminación que resultó de la intersección de dichos factores, es decir, si alguno de dichos factores no hubiese existido, la discriminación habría tenido una naturaleza diferente (\$290).

Recientemente, en el caso Trabajadores de Hacienda Brasil Verde us. Brasil (2016), la Corte IDH incorporó al criterio pobreza como implícito a la categoría «posición económica» en el artículo 1.1 de la CADH. Para la Corte IDH,

[...] toda persona que se encuentre en una situación de vulnerabilidad es titular de una protección especial, en razón de los deberes especiales cuyo cumplimiento por parte del Estado es necesario para satisfacer las obligaciones generales de respeto y garantía de los derechos humanos. El Tribunal recuerda que no basta con que los Estados se abstengan de violar los derechos, sino que es imperativa la adopción de medidas positivas, determinables en función de las particulares necesidades de protección del sujeto de derecho, ya sea por su condición personal o por la situación específica en que se encuentre, como la extrema pobreza o marginación (§ 337).

La Corte IDH identificó en este caso una situación de discriminación estructural y afirmó que «el Estado incurre en responsabilidad internacional en aquellos casos en que, habiendo discriminación estructural, no adopta medidas específicas respecto a la situación particular de victimización en que se concreta la vulnerabilidad sobre un círculo de personas individualizadas» (\$ 338). Sobre el reconocimiento de la pobreza como criterio prohibido de discriminación, el juez Eduardo Ferrer Mac-Gregor señaló en un voto razonado que

[...] la posición económica alude a situaciones estructurales de negación, por diversas circunstancias, a un sector de la población, de necesidades generales de vida digna y autónoma. Debe entenderse, pues, dentro del conjunto de situaciones que impiden que una persona desarrolle una vida digna, como el acceso y disfrute a los servicios sociales más básicos (2016, §54).

Asimismo, sobre la metodología adoptada por el tribunal interamericano para identificar nuevas categorías sospechosas de discriminación, resaltó que estas «han respondido a las realidades sociales que se han ido presentando con la evolución de las mismas; en donde, además no se vinculan de manera individual sino que responden a diversos factores y barreras sociales y culturales de manera conjunta» (§ 55). Así, para el presidente de la Corte IDH, «resulta necesario entender la no discriminación a la luz de una situación de desventaja que presentan algunos grupos y por lo tanto los pueden someter a condiciones históricas de discriminación, que en ocasiones se encuentran avaladas por la sociedad» $(\S 79)$. 
Por su parte, Ferrer Mac-Gregor, a partir de la jurisprudencia previa de la Corte IDH, propone una serie de elementos que pueden ser tomados en consideración a fin de identificar a un grupo vulnerable susceptible de ser protegido por el artículo 1.1 de la CADH. En primer lugar, se trataría de «un grupo o grupos de personas que tienen características inmutables o inmodificables por la propia voluntad de la persona o bien que están relacionados a factores históricos de prácticas discriminatorias, pudiendo ser este grupo de personas minoría o mayoría» (\$ 80). En segundo lugar, dada la situación de subordinación sistemática e histórica de la que han sido víctimas estos grupos, sus miembros se encuentran impedidos de «acceder a condiciones básicas de desarrollo humano» (\$ 80). En tercer lugar, que dicha situación de discriminación puede limitarse a un territorio geográfico determinado o a todo el territorio de un Estado, y que puede prolongarse a través de diferentes generaciones en el tiempo. Por último, que los integrantes de estos grupos «son víctimas de discriminación indirecta o bien de discriminación de facto, por las actuaciones o aplicación de medidas o acciones implementadas por el Estado» ( $\$ 80)$. Tan solo un mes más tarde, en la sentencia del caso I.V. vs. Bolivia (2016), la Corte IDH incorporó al listado de criterios sospechosos del artículo 1.1. de la CADH la condición de persona refugiada (\$240). En relación con la metodología para la identificación de nuevos criterios sospechosos, la Corte afirma que estos responden a «i) rasgos permanentes de las personas de los cuáles estas no pueden prescindir sin perder su identidad; ii) grupos tradicionalmente marginados, excluidos o subordinados; y iii) criterios irrelevantes para una distribución equitativa de bienes, derechos o cargas sociales». Reiterando su anterior jurisprudencia, la Corte afirma que, «cuando se trata de una medida que establece un trato diferenciado en que está de por medio una de estas categorías, la Corte debe aplicar un escrutinio estricto que incorpora elementos especialmente exigentes en el análisis» ( $\$ 241)$. Entre otros, busca que la finalidad de la medida sea no solo legítima, sino además imperiosa; que la medida sea no solo idónea, sino necesaria; y que los beneficios de adoptar la medida en cuestión sean «claramente superiores a las restricciones que ella impone a los principios convencionales afectados con la misma» (\$241). No obstante, aunque en este caso la Corte identificó la categoría «persona en condición de refugiada» como sospechosa, esta no fue el principal lente de análisis. La Corte aplicó el enfoque de la «discriminación múltiple» y determinó que en el caso de la señora I.V. convergieron diversos factores de discriminación, como su condición de mujer, su origen nacional (peruana) y su posición económica. Más aún, la protección estricta del artículo 1.1 se activó en razón de la discriminación por sexo y género de la que fue víctima la señora I.V. al haber sido objeto de estereotipos en relación con la toma de decisiones reproductivas (\$243). Una vez aplicado el examen de escrutinio estricto, la Corte encontró que, aunque

¿SOSPECHAR

PARA IGUALAR?

UN ANÁLISIS

«ESTRICTO»DE

LA DOCTRINA DE

LAS CATEGORÍAS

SOSPECHOSAS

a PARTIR DE LA

JURISPRUDENCIA

DEL TRIBUNAL

CONSTITUCIONAL

PERUANO

Y LA CORTE

INTERAMERICANA

DE DERECHOS

HUMANOS

TO SUSPECT

IN ORDER

TO EQUATE?

$A$ «STRICT»

SCRUTINY OF

THE SUSPECT

CLASSIFICATIONS

DOCTRINE FROM

THE CASE LAW OF

THE PERUVIAN

CONSTITUTIONAL

COURT AND THE

INTER-AMERICAN

COURT OF HUMAN

RIGHTS 
la decisión de practicar la ligadura de trompas de Falopio a la señora I.V. no obedeció a su origen nacional, posición económica o condición de refugiada, estos factores «incidieron sobre la magnitud de los daños que sufrió I.V. en la esfera de su integridad personal» (§ 248). La Corte IDH encontró la responsabilidad del Estado por discriminación en razón de la condición de mujer de la señora I.V., toda vez que el proceso de esterilización anuló de forma discriminatoria su poder decisorio al no haber prestado su consentimiento y haberse buscado la confirmación de su esposo, lo que, en opinión de la Corte, demostró «que actuó bajo el estereotipo de que ella no era capaz de tomar una decisión autónoma sobre su cuerpo» (§ 246).

En pronunciamientos anteriores a los reseñados, la Corte IDH había extendidoel número de criterios prohibidos de discriminación enunciados en el artículo 1.1 de la $\mathrm{CADH}^{5}$. Así, incluyó entre estos al «género», y reemplazó el criterio «posición económica» por el de «situación económica», y el criterio «opiniones políticas» por el de «opinión política», sin dar mayores explicaciones (Dulitzky, 2010, p. 580). En esa línea, sin aludir necesariamente al artículo 1.1, la Corte ha identificado a otros grupos sociales como vulnerables y les ha concedido una protección especial, tal es el caso de las personas con discapacidad (Ximenes Lopes vs. Brasil, 2006; Furlán y familiares vs. Argentina, 2012; Artavia Murillo y otros vs. Costa Rica, 2012), la de los migrantes indocumentados (Nadege Dorzema y otros vs. República Dominicana, 2012) y, más recientemente, la de las personas adultas mayores (Poblete Vilches y otros vs. Chile, 2018) ${ }^{6}$.

De lo antes expuesto, puede concluirse que la Corte IDH justifica la incorporación de nuevos criterios sospechosos, primero remitiéndose a los contenidos de las cláusulas de igualdad de otros tratados de derechos humanos - como sucedió en el caso de la inclusión del criterio «etnia» (Norín Catrimán y otros ws. Chile, 2014, § 202)—, así como a las decisiones y opiniones de otros tribunales internacionales y organismos de seguimientos de tratados - como sucedió en el caso de la inclusión de los criterios «orientación sexual» $\mathrm{y}$ «condición de persona con $\mathrm{VIH}$ »Segundo, en la mayoría de las ocasiones esta justificación formal se ve reforzada por una de carácter material, la que se configuraría cuando un criterio coincide con la identificación de nuevos grupos vulnerables, los que habrían sido objeto de una discriminación de tipo histórico y estructural. Lo vemos así en el caso de las «minorías sexuales», «personas que padecen VIH», «migrantes indocumentados», «personas con discapacidad», «personas adultas mayores» y «personas en situación

5 A la letra: «Artículo 1.- Los Estados partes en esta Convención se comprometen a respetar los derechos y libertades reconocidos en ella y garantizar su libre y pleno ejercicio a toda persona que esté sujeta a su jurisdicción, sin discriminación alguna por motivos de raza».

6 Para conocer sobre la doctrina del Tribunal Europeo de Derechos Humanos en materia de protección de grupos vulnerables, puede consultarse Peroni (2013) y Arnardóttir (2017). 
de pobreza». Si bien en la sentencia del caso I.V. vs. Bolivia la Corte IDH estimó que un criterio sospechoso debería también configurar un rasgo permanente identitario, así como un factor irrelevante para la distribución de derechos, bienes o cargas sociales, dichos estándares no han alcanzado todavía un grado de continuidad jurisprudencial, por lo que sería prematuro valorarlos en estricto como requisitos de una categoría sospechosa. Tercero, la Corte IDH incorpora también nuevos contenidos a los criterios de discriminación prohibidos explícitamente por la $\mathrm{CADH}$, tal es el caso de la línea editorial de un medio de comunicación o de la situación de pobreza. Cuarto, aunque no ha sido señalado de modo explícito en todos los casos — salvo en Atala Riffo vs. Chile (2012, § 131); González Lluy vs. Ecuador; Granier, Radio Caracas Televisión vs. Venezuela; I.V. vs. Bolivia-, la Corte IDH aplica un examen de gradación de escrutinios para la evaluación de posibles violaciones de los artículo 1.1 y 24 de la CADH, el que enmarca dentro del principio de proporcionalidad, también acogido por su jurisprudencia.

Hasta este punto del trabajo, podemos apreciar que existen varias similitudes entre la jurisprudencia del TC peruano y la Corte IDH en lo referido a las categorías sospechosas. En primer lugar, ambos tribunales han coincidido en cuanto al principio material subyacente a la consideración de un criterio como sospechoso: la identificación de nuevos grupos en situación de vulnerabilidad. Segundo, ambos tribunales concuerdan en la selección de la herramienta hermenéutica adecuada para evaluar una supuesta situación de discriminación: se trata del examen de escrutinio estricto, el que implica una presunción de inconstitucionalidad o inconvencionalidad de la medida diferenciadora, la que es vencida si dicha medida persigue un objetivo social imperioso, representa la medida menos lesiva entre las opciones posibles, y no sacrifica principios o derechos fundamentales de mayor peso que el bien cuya realización persigue la medida en cuestión. No obstante las similitudes antes mencionadas, cada tribunal ha dado lugar a distintos desarrollos doctrinales. Así, por ejemplo, el TC ha recogido la doctrina de los acomodamientos razonables y la discriminación indirecta, mientras que la Corte IDH ha esbozado los primeros trazos de una doctrina jurisprudencial de la discriminación interseccional y discriminación estructural. Del mismo modo, encontramos que la Corte IDH ha sido más proclive a la identificación de nuevos criterios sospechosos que el TC peruano, habiendo reconocido como categorías sospechosas a la orientación sexual, el origen étnico, la condición de VIH positivo, la línea editorial de un medio de comunicación, la pobreza, la discapacidad y la condición de adulto mayor, de refugiado y la de migrante; mientras que el TC peruano ha procedido en ese sentido solo respecto de la condición de discapacidad y la de adulto mayor.

¿SOSPECHAR

PARA IGUALAR?

UN ANÁLISIS

«ESTRICTO» DE

LA DOCTRINA DE

LAS CATEGORÍAS

SOSPECHOSAS

a partir de la

JURISPRUDENCIA

DEL TRIBUNAL

CONSTITUCIONAL

PERUANO

Y LA CORTE

INTERAMERICANA

DE DERECHOS

HUMANOS

TO SUSPECT

IN ORDER

TO EQUATE?

$A$ «STRICT»

SCRUTINY OF

THE SUSPECT

CLASSIFICATIONS

DOCTRINE FROM

THE CASE LAW OF

THE PERUVIAN

CONSTITUTIONAL

COURT AND THE

INTER-AMERICAN

COURT OF HUMAN

RIGHTS 


\section{IV.UN ANÁLISIS ESTRICTO DE LA DOCTRINA DE LAS "CATEGORÍAS SOSPECHOSAS»}

\section{IV.1. La igualdad de grupo bajo examen}

Esta comprensión del principio de igualdad y no discriminación como protección de grupos sistemáticamente excluidos, adoptada por el TC y la Corte IDH, ha sido abordada desde distintos ángulos por la doctrina. Así, por ejemplo, Barrere y Morondo, en su intento de reconstrucción del principio de no discriminación, consideran que este se inscribe en el «discurso sobre el poder»; en concreto, «en términos de opresión y/o dominación» (2011, p. 18), los que Young entiende como aquellos

[...] impedimentos sistemáticos que sufren algunos grupos y que no necesariamente son el resultado de las intenciones de un tirano $[\ldots]$ Sus causas están insertas en normas, hábitos y símbolos que no se cuestionan [...] El carácter sistémico de la opresión determina que un grupo oprimido no necesite tener un grupo opresor correlativo. Como podemos apreciar, lo esencial de esta comprensión del principio de igualdad y no discriminación reside en identificar grupos sociales sujetos a condiciones de marginalidad, con el objeto de ponerle fin a tal exclusión (1990, pp. 74-75).

Encontramos también la propuesta de Roberto Saba, quien asocia la idea de «no discriminación» a la de «no sometimiento» (2009, p. 731). Ello implica que el principio de no discriminación tendría como fin reconocer aquellas prácticas sociales que sitúan a algunos grupos sociales en una situación de desventaja, así como develarlas y mejorar la posición social de estos grupos con el objeto de que sus miembros salgan de su situación de marginación. De modo similar, para Clérico, la aplicación de este principio prescribe que el Estado tendría no solo el deber de abstenerse de cometer actos discriminatorios, sino de realizar acciones positivas, así como de revisar aquellas normas que, aunque neutrales en apariencia, tengan un impacto negativo sobre los grupos en situación de exclusión (2012, p. 133). Estas medidas de acción positiva pueden tener como finalidad, por un lado, la «redistribución» —es decir, un rediseño del reparto de bienes de tipo económico a fin de transformar las relaciones de producción —; y, de otra parte, el «reconocimiento» de identidades dominadas a fin de permitir el acceso igualitario de estas a los patrones culturales y recursos simbólicos (Clérico \& Aldao, 2011, p. 152).

Esta comprensión del principio de igualdad configuraría una «superación» del modelo clásico de igualdad como «no arbitrariedad» (Fiss, 1976, pp. 129-146). Para Owen Fiss, por medio de esta noción se introduce la relevancia en el mundo jurídico del concepto «grupo vulnerable» o «grupo desaventajado», y se transforma el examen de igualdad 
en un análisis sobre la posición de los diferentes grupos sociales y sus interacciones, más que en un análisis de la situación individual de un sujeto (1976, p. 147). Asimismo, se reemplaza la noción de clasificación arbitraria por la de «clase» o «casta», con lo que la protección del principio de igualdad y no discriminación vira de su carácter simétrico (es decir, la protección uniforme de todos los grupos posiblemente afectados por una determinada categoría — «blancos» al igual que «negros», «hombres» al igual que «mujeres»-) a uno de tipo asimétrico, el mismo que observa que no es lo mismo diferenciar por razón del origen étnico a una persona «criolla» que a una «indígena», por lo que justifica un trato desigual «con el fin de desmantelar la situación de exclusión estructural de ciertos grupos sociales» (p. 731).

En ese sentido, como afirma Saba,

[...] al dejar de ser la irrazonabilidad palmaria la que torna sospechosa a la categoría, y pasar a ser relevante su relación con la perpetuación de una situación de desigualdad estructural, exclusión o marginalización que la Constitución ordena desmantelar, no habría categorías sospechosas a priori, sino que se deberá analizar cada categoría en particular y el impacto del trato diferente operado en función de ella en la situación del grupo específico del que se trate. Si ese grupo es un grupo sistemática e históricamente excluido, segregado o marginalizado, estructuralmente tratado en forma desigual, y si el trato derivado del recurso a esa categoría perpetúa o profundiza su condición, entonces esa categoría será sospechosa (2009, p. 731).

Esta manera de comprender el principio de igualdad y no discriminación tiene un eje grupal definitorio, por lo que autores como Fiss han desarrollado una teoría de identificación de los caracteres constitutivos de un grupo social. En primer lugar, todo grupo es una entidad, y como tal tiene una existencia distinta a la de sus miembros en tanto posee una identidad como grupo. En segundo lugar, hay una relación de interdependencia entre el bienestar de los miembros del grupo a nivel individual y el bienestar del grupo como tal. En tercer lugar, se trata de un grupo marginado en la historia, no solo en razón de su estatus socioeconómico, sino por su estatus político, el que se ve reducido por su presencia numérica y el prejuicio del que es víctima, lo que dificulta su capacidad para asociarse y formar coaliciones con los miembros de otros grupos sociales, siendo particularmente proclives al abuso de las mayorías (1976, pp. 148-149). Por otro lado, esta aproximación reconoce que entre los distintos grupos sociales existen relaciones de poder, las que se fundarían sobre la base de prejuicios y estereotipos irracionales muchas veces involuntarios.

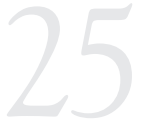

¿SOSPECHAR

PARA IGUALAR?

UN ANÁLISIS

«ESTRICTO»DE

LA DOCTRINA DE

LAS CATEGORÍAS

SOSPECHOSAS

A PARTIR DE LA

JURISPRUDENCIA

DEL TRIBUNAL

CONSTITUCIONAL

\section{PERUANO}

Y LA CORTE

INTERAMERICANA

DE DERECHOS

HUMANOS

TO SUSPECT

IN ORDER

TO EQUATE?

$A$ «STRICT»

SCRUTINY OF

THE SUSPECT

CLASSIFICATIONS

DOCTRINE FROM

THE CASE LAW OF

THE PERUVIAN

CONSTITUTIONAL

COURT AND THE

INTER-AMERICAN

COURT OF HUMAN

RIGHTS 
De manera similar a las propuestas antes citadas, el TC y la Corte IDH se han concentrado sobre todo en el estatus de subordinación cultural a fin de identificar nuevos grupos vulnerables. Así, por ejemplo, cuando el TC reconoce a la edad como criterio sospechoso, le preocupan sobre todo los «estereotipos vinculados a la vejez» (María Chura Arcata vs. Banco de la Nación, 2017, § 9), tales como la inoperancia, el déficit de autonomía y la dificultad autopercibida para «acceder a distintos medios de realización personal» (§ 9). De otra parte, el voto razonado del juez Ferrer Mac-Gregor, citado supra, evidencia claramente esta tendencia en la jurisprudencia de la Corte IDH. En este sentido, podemos afirmar que tanto el TC como la Corte IDH asemejan las «condiciones históricas de marginación» a prejuicios subyacentes sobre las capacidades y aptitudes de determinados grupos sociales, situación que buscan remediar con sus fallos.

Si bien consideramos valiosos varios de los aportes de esta aproximación al principio de no discriminación, especialmente el hecho de que permite identificar situaciones de desventaja relativa que afectan a las personas en el ejercicio de sus derechos por el solo hecho de pertenecer a un grupo social, creemos no obstante que es necesario matizar algunos de sus alcances. Nos concierne, sobre todo, el referido a la relación de interdependencia entre el bienestar del grupo como un todo y el bienestar de sus miembros considerados individualmente. Por ejemplo, para Hellman, este enfoque, al centrar la injusticia de un acto discriminatorio en la desventaja que ocasiona a los miembros de un determinado grupo social, tiene el grave costo de minimizar las consecuencias de dicho acto para el individuo que lo ha padecido. Para la autora, por el contrario, el daño producido por un acto discriminatorio es relevante en tanto afecta a un individuo en particular y no solo a un grupo social como tal (2008, p. 23).

Asimismo, la doctrina de las identity politics, que sirve de base para las concepciones de igualdad como «reconocimiento», ha sido criticada desde la ciencia política (Minow, 1992; Iyer, 1993). Estas críticas han sido trasladadas al ámbito del derecho antidiscriminatorio por Sujit Choudry y Sonu Bedi, propuestas que abordaremos con mayor detalle a continuación. Para Choudry, el paradigma de la igualdad de grupo adolece de una grieta surgida de la tensión redistribuciónreconocimiento. En el paradigma de redistribución, el propósito de las normas de no discriminación sería la protección de los derechos de los individuos, de modo que estos sean los artífices de sus elecciones y obtengan mejores oportunidades en razón de su propio mérito, y no por acción de prejuicios y circunstancias externas a su propia voluntad. En esa línea, las categorías sospechosas obedecerían a ejemplos de características personales que resultarían irrelevantes para la distribución de cargas económicas, no así para la afirmación de la identidad de los 
grupos sociales vulnerables definidos a partir de dichas características (2000, p. 154). Por el contrario, para el paradigma de reconocimiento, los grupos sociales vulnerables serían la única fuente de categorías sospechosas, toda vez que la discriminación sistemática de la que son víctimas sus integrantes resultaría fruto de la subyugación cultural de dichos grupos y de los prejuicios y estereotipos originados a partir de esta. En ese sentido, las categorías sospechosas no son solo ejemplos de criterios irrelevantes de distribución, sino que enumeran (aunque no de manera exhaustiva) a grupos sociales dominados. De lo que se trataría, entonces, es de identificar las características más resaltantes de dichos grupos para agruparlas en criterios prohibidos de discriminación y procurar a partir de ello el cese de su subyugación cultural (2000, p. 158).

La tensión surge cuando para el paradigma de la redistribución el principal propósito de las cláusulas de no discriminación es remediar la desigualdad económica de los individuos a fin de darles mayores niveles de autonomía, mientras que para el paradigma de reconocimiento se trata de reconocer la valía de un determinado grupo social y de su cultura común o modo de vida; no obstante, el mismo grupo social cuyo reconocimiento busca obtenerse podría ser también una fuente de opresión para la autonomía de los individuos. En consecuencia, para Choudry, el modo como se ha ido perfilando la doctrina de las categorías sospechosas, bajo el paradigma del reconocimiento, ha llevado a que los tribunales subsuman a los individuos que reclaman un acto discriminatorio en una categoría que no necesariamente se ajusta a los matices de su individualidad. Son también los tribunales quienes determinan las características de los grupos que se adscriben a una determinada categoría, enfatizando las semejanzas más resaltantes entre los miembros del grupo y acentuando sus diferencias con respecto a los individuos que no forman parte de este, de modo que las diferencias entre los mismos miembros del grupo suelen pasar desapercibidas (2000, p. 167). Asimismo, no debería olvidarse que por las exigencias de seguridad jurídica, dichas categorías deberían mantener cierta coherencia y estabilidad en el tiempo, lo que podría dar lugar a categorías identitarias rígidas, permanentes o inamovibles (p. 168). De esa forma, algunos individuos son o simplemente dejados de lado o diluidos en un grupo al que no pertenecen (Minow, 1997, p. 79).

En suma, la fuente del prejuicio y los estereotipos se trasladaría de la sociedad hacia los tribunales, de modo que, para resultar exitoso en una demanda de discriminación, los individuos afectados deberían subordinar su propio entendimiento de su identidad a los parámetros fijados por los tribunales (cuando, quizá, los parámetros que definen al grupo no pueden ni siquiera ser fijados por sus propios integrantes). Más aún, en algunos casos, los individuos podrían verse forzados a adoptar los parámetros identitarios del grupo al que «deberían

¿SOSPECHAR

PARA IGUALAR?

UN ANÁLISIS

«ESTRICTO» DE

LA DOCTRINA DE

LAS CATEGORÍAS

SOSPECHOSAS

a partir de la

JURISPRUDENCIA

DEL TRIBUNAL

CONSTITUCIONAL

PERUANO

Y LA CORTE

INTERAMERICANA

DE DERECHOS

HUMANOS

TO SUSPECT

IN ORDER

TO EQUATE?

$A$ «STRICT»

SCRUTINY OF

THE SUSPECT

CLASSIFICATIONS

DOCTRINE FROM

THE CASE LAW OF

THE PERUVIAN

CONSTITUTIONAL

COURT AND THE

INTER-AMERICAN

COURT OF HUMAN

RIGHTS 
pertenecer» por sus características, ya que una vez que el «derecho» ha definido las características de ese grupo, entonces queda menor espacio para la discusión sobre los términos identitarios al interior del mismo, para asumir más bien aquellos externos que han sido aprobados por el derecho (Choudry, 2000, p. 176). Esto podría tener como lamentable consecuencia que un tribunal pase por alto situaciones de injusticia e irrazonabilidad en la asignación de bienes y cargas hacia un individuo, por el solo hecho de que este no pertenece a un grupo social vulnerable caracterizado en sus propios términos, esquemas y paradigmas.

El esencial carácter «grupal» de la doctrina de las categorías sospechosas ha sido también cuestionado por Sonu Bedi. En su opinión, para que un grupo sea considerado como objeto de protección de una categoría sospechosa, debe alegar enfáticamente su estatus como históricamente oprimido; en consecuencia, los miembros de un grupo deberían definirse a sí mismos como víctimas de un sistema opresor para distinguirse del resto, lo que tendría como consecuencia negativa que se acentúen los estigmas y estereotipos contra estas poblaciones. Más aún, esta lógica contravendría el sentido del principio de «igualdad fundante»(2013, p. 47) al oscurecer las semejanzas esenciales entre los seres humanos para acentuar sus diferencias contingentes. De otra parte, el autor afirma que la lógica de las categorías sospechosas amenazaría las posibilidades de un individuo para moldear, revisar o alterar su identidad y consecuente pertenencia a un determinado grupo social (p. 58). Asimismo, considera que no resulta conveniente que las cortes resuelvan casos de discriminación bajo la lógica de una identity claim, pues ello reforzaría la objeción contramayoritaria al control judicial de la constitucionalidad y dificultaría los caminos para la toma de decisiones consensuadas. Si una corte constitucional tomase la decisión de revertir una decisión de la mayoría legislativa para favorecer a un grupo vulnerable y minoritario (por más justas que sean sus exigencias), no podría luego pretender no ser criticada por reconocer «derechos especiales» o por incurrir en «activismo judicial» (p. 62). La retórica de los derechos especiales acentuaría el conflicto, el «nosotros» contra «ellos», alejando las posibilidades de un debate constructivo (p. 63).

Consideramos que debe prestarse atención a las críticas mencionadas antes de sugerir un enfoque exclusivo y excluyente del principio de no discriminación como protección de grupos vulnerables, tanto en el derecho constitucional peruano como en el interamericano, toda vez que dejarlas de lado podría significar desatender las demandas concretas de justiciables que, sin pertenecer o identificarse con un determinado grupo social vulnerable, son víctimas de injusticias graves como consecuencia de un trato arbitrario e irrazonable por parte del Estado. A nuestro parecer, no es coherente con la lógica del principio de igualdad el negarle la protección a un individuo, víctima de un trato 
desigual arbitrario por parte del Estado, por el solo hecho de no pertenecer a un grupo vulnerable. La lógica de la igualdad como «no sometimiento» en el ámbito de la doctrina de las categorías sospechosas deja a los jueces del TC peruano y de la Corte IDH en la posibilidad de decidir qué grupos están in y merecen, por tanto, la protección reforzada de un criterio sospechoso; y cuáles están out. Asimismo, deja en las manos de los jueces la calificación jurídica de las características salientes de un determinado grupo vulnerable, forzando -quizá con las mejores intenciones- la definición que de ese grupo harán sus propios integrantes y encogiendo así los caminos de la pluralidad propia de las comunidades humanas.

En nuestra opinión, el análisis de las estructuras sociales que han propiciadoladiscriminación en determinados contextos resultarelevante, pero no puede ser el único prisma bajo el que se mire el principio de no discriminación. Ciertamente, la situación de desigualdad que afecta a un individuo puede verse condicionada por la posición que ocupa en la estructura social, pero no necesariamente viene determinada por ella (Elósegui, 2011). Consideramos que el sobreesfuerzo por clasificar a un individuo dentro de un determinado grupo y asemejar dicha situación a un criterio sospechoso explícito (o, vía interpretación evolutiva, «descubrir» uno implícito) resulta de poca ayuda para el develamiento de una situación discriminatoria que lo posterga y desaventaja. En nuestra opinión, el principio de no discriminación no busca la mera igualdad de grupo, sino la protección de las personas (cada una de ellas) que pertenecen a esos grupos desaventajados (Khaitan, 2015, p. 138) o que, sin pertencer a uno de ellos, han sufrido un trato desigual arbitrario para el ejercicio de un derecho fundamental. A fin de lograr dicho propósito, puede resultar conveniente que el legislador identifique como criterios prima facie prohibidos de discriminación ciertas características personales (puede tratarse de características que representen rasgos u opciones valiosas en la vida de las personas para la conformación de su identidad) que permiten clasificar a las personas en grupos y que colocan en una situación de desventaja relativa a algunos grupos sociales con respecto a otros dentro de la misma categoría (p. 42). Para ello, el legislador (y, cuando corresponda, el juez) deberán prestar particular atención a los fenómenos sociales que rodean a los individuos y grupos adscritos a una determinada categoría, pues la raíz de su desventaja puede encontrarse en prejuicios y estereotipos de carácter irrazonable.

Asimismo, centrarse solo en las estructuras de opresión que afectan a los diferentes grupos sociales pierde de vista la diversidad existente al interior de los grupos sociales y cómo sus miembros son afectados de modo distinto por dichas estructuras. Esto se manifiesta en la sentencia del caso González Lhy vs. Ecuador, en el que la Corte IDH analizó la situación concreta de discriminación que padeció la niña González Lluy, la cual evidenció la confluencia de múltiples factores que acentuaron

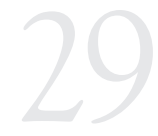

¿SOSPECHAR

PARA IGUALAR?

UN ANÁLISIS

«ESTRICTO» DE

LA DOCTRINA DE

LAS CATEGORÍAS

SOSPECHOSAS

A PARTIR DE LA

JURISPRUDENCIA

DEL TRIBUNAL

CONSTITUCIONAL

PERUANO

Y LA CORTE

INTERAMERICANA

DE DERECHOS

HUMANOS

TO SUSPECT

IN ORDER

TO EQUATE?

$A$ «STRICT»

SCRUTINY OF

THE SUSPECT

CLASSIFICATIONS

DOCTRINE FROM

THE CASE LAW OF

THE PERUVIAN

CONSTITUTIONAL

COURT AND THE

INTER-AMERICAN

COURT OF HUMAN

RIGHTS 
su vulnerabilidad, entre otros su situación de pobreza, su condición de persona con VIH y su condición de mujer, que le permitieron reconocer, por ejemplo, que «la estigmatización relacionada con el VIH no impacta en forma homogénea a todas las personas» (2015, § 290). Del mismo modo, centrarse en los grupos sociales vulnerables pierde de vista que las personas fuera de estos grupos son también vulnerables. En esa línea, propuestas como la de Fineman ponen de relieve una realidad fácilmente constatable: el carácter universal y constante de la vulnerabilidad de todos los seres humanos, la que no obstante se experimenta de manera única y variada a nivel individual ${ }^{7}$ (2012, p. 1713).

En consonancia con lo antes mencionado, proponemos dejar atrás el paradigma de las categorías sospechosas de discriminación para adoptar el enfoque de las «situaciones sospechosas de discriminación», el mismo que implica para el juez constitucional e interamericano tener en cuenta tanto el contexto general de la medida diferenciadora — es decir, «las condiciones históricas, sociales, políticas y económicas que envuelven la vida de las personas que habitan la categoría respectiva» (Saldivia, 2011, p. 41) - como las circunstancias concretas de la persona afectada por dicha medida al momento de resolver una controversia de no discriminación. Por consiguiente, el juzgador deberá prestar atención primero al hecho de que no siempre una diferencia de trato, para calificarse como potencialmente discriminatoria, debe fundarse en la pertenencia de un individuo o conjunto de personas a un determinado grupo social con rasgos identitarios fuertes; $y$, segundo, que no toda diferenciación contra un grupo con rasgos identitarios fuertes merece ser sancionada por el derecho, sobre todo si este último resulta pernicioso para el individuo (Khaitan, 2015, p. 136).

No debe olvidarse que «[...] la aplicación del principio de igualdad implica juicios de valor y es una tarea parcialmente creativa» (Fernández, 2003, p. 78) que se divide entre su carácter universal y su aplicación para la solución de la controversia concreta, para la cual necesita ser interpretado, actualizado y contextualizado de modo objetivo. En nuestra opinión, no todos los criterios explícitamente señalados como «prohibidos de discriminación» serán siempre objeto de sospecha, no lo son tampoco solo aquellos que responden a una característica personal que representa un rasgo identitario fuerte de un grupo vulnerable. Consideramos que lo que existen son más bien situaciones sospechosas de discriminación, las que el juez dilucida a partir de los hechos y circunstancias del caso concreto y en las que valora no solo el entramado social histórico que rodea a una persona, sino también el grado en el que la acción legislativa o administrativa degrada a esa persona como titular

7 Para una aproximación crítica a esta posición puede consultarse Barrere (2016). 
de igual valor que otros seres humanos (Hellman, 2008, p. 8) y genera desventajas para su desarrollo.

\section{IV.2.El escrutinio estricto bajo sospecha}

Tanto el TC como la Corte IDH han optado por aplicar el examen de escrutinio estricto a distinciones realizadas sobre la base de una categoría sospechosa. El examen de escrutinio estricto fue inicialmente formulado por la Corte Suprema de los Estados Unidos en la nota al pie de la sentencia del caso Carolene Products. Esta señala:

[E]l prejuicio contra minorías discretas e insulares puede ser una condición que limit[e] seriamente el funcionamiento de aquello procesos políticos en los que regularmente podemos confiar para la protección de las minorías, y [así] puede requerir de una mayor supervisión judicial (United States vs. Carolene Products Co., 1938, § 152. Traducción de Biscardi \& Garibotti, 2009, p. 125).

La racionalidad detrás de este mandato residiría, para Ely, en su naturaleza correctora de las disfuncionalidades de los procesos democráticos (1980, p. 101). A su juicio, estas ocurren cuando los detentores del poder ahogan los canales de cambio con el fin de asegurar su permanencia en el mismo y la exclusión de nuevos actores; o cuando, si bien no se niega el voto o la voz a una minoría, la mayoría genera sistemáticamente desventajas a algunos grupos minoritarios sobre la base de una simple hostilidad o una negativa prejuiciosa a reconocer puntos comunes de interés, lo que los deja fuera del sistema representativo (pp. 101-104). Esto último significa que en numerosas ocasiones la mayoría no representa adecuadamente los intereses de ciertos grupos minoritarios, situación que se acentúa cuando la discriminación de estos está arraigada históricamente, toda vez que en dichos casos la mayoría puede actuar sobre la base de estereotipos negativos o de mera hostilidad hacia el grupo minoritario.

El examen de escrutinio estricto en la fórmula norteamericana se aplica a las distinciones basadas sobre aquellos criterios que la Corte Suprema ha declarado sospechosos, tales como la raza, el origen nacional y la condición de extranjero. Este examen se compone de los siguientes pasos (Giardelli et al., 2005, pp. 318-319):

1. La carga de la prueba recae sobre el demandado.

2. En el juicio de adecuación, se demanda que el legislador persiga una finalidad imperiosa o compelling state interest. Asimismo, se requiere un estrecho margen de adecuación entre medio y fin (narrowly tailored), de forma que la medida aparentemente discriminatoria no pasará el test si se comprueba que es underinclusive (que deja fuera casos que debió incluir).

¿SOSPECHAR

PARA IGUALAR?

UN ANÁLISIS

«ESTRICTO» DE

LA DOCTRINA DE

LAS CATEGORÍAS

SOSPECHOSAS

A PARTIR DE LA

JURISPRUDENCIA

DEL TRIBUNAL

CONSTITUCIONAL

PERUANO

Y LA CORTE

INTERAMERICANA

DE DERECHOS

HUMANOS

TO SUSPECT

IN ORDER

TO EQUATE?

$A$ «STRICT»

SCRUTINY OF

THE SUSPECT

CLASSIFICATIONS

DOCTRINE FROM

THE CASE LAW OF

THE PERUVIAN

CONSTITUTIONAL

COURT AND THE

INTER-AMERICAN

COURT OF HUMAN

RIGHTS 
3. En el juicio de necesidad se exige que la medida sea indispensable para el logro del fin; es decir, que resulte la menos gravosa y sea, al mismo tiempo, igualmente eficaz. La medida no pasará el test si se comprueba que es overinclusive (que abarca casos que debió dejar de lado).

4. Una vez realizado el juicio de proporcionalidad, se optará por declarar la inconstitucionalidad de la medida si queda duda sobre su constitucionalidad.

Como vimos anteriormente, el TC y la Corte IDH aplican un test de escrutinio estricto a las diferenciaciones basadas en criterios sospechosos. Si bien el TC ha planteado un sistema de niveles de escrutinio, en el que el más grave se aplica a las diferenciaciones basadas en categorías sospechosas que, a la vez, limitan el goce de derechos fundamentales; no queda claro, a partir de la jurisprudencia de la Corte IDH, que esta aplique también estos niveles de escrutinio, sino más bien un modelo de «balanza calibrada», semejante al del Tribunal Europeo de Derechos Humanos y la Corte Europea de Justicia, en el que la intensidad del examen varía en función a distintos criterios, encontrando un test estricto, uno débil y, en medio, varias áreas grises o modelos híbridos (Gerards, 2004, p. 140). Sin perjuicio de lo antes señalado, podemos encontrar algunas semejanzas entre el test norteamericano y los aplicados por el TC y la Corte IDH. Así, por ejemplo, los tres exámenes exigen razones justificadoras de mucho peso para la medida presuntamente discriminatoria, así como un diligente juicio de necesidad y estricta proporcionalidad, la inversión de la carga de la prueba y la presunción de inconstitucionalidad de la medida. No obstante lo señalado, la pregunta que nos hacemos y que resulta relevante que se hagan también tanto el TC peruano como la Corte IDH es si, en el fondo, el examen de escrutinio estricto asegura mayores niveles de rigurosidad y objetividad al momento de resolver una controversia de no discriminación.

Bedi, analizando el test de escrutinio estricto de la Corte Suprema de EE. UU., nota que dicho examen no sería tan objetivo ni riguroso como pretende, toda vez que deja a la libre interpretación del juzgador, en primer lugar, qué criterios merecen tal análisis; en segundo lugar, qué fines son susceptibles de considerarse «imperiosos» o de calificarse como «razones de mucho peso»; y, en tercer lugar, qué significa una «adecuación estrecha entre medios y fines» (2013, p. 41). Todas estas tareas son sin duda actividades de tipo valorativo que pueden verse sujetas a mayores o menores grados de arbitrariedad, los que el juicio de escrutinio estricto no puede evitar, a pesar de su esquematización. En esa línea, no queda claro, a partir de la jurisprudencia del TC peruano, qué fines han de ser considerados imperiosos, toda vez que aunque ha indicado en su doctrina jurisprudencial que debe aplicarse un escrutinio estricto 
respecto de criterios sospechosos, este se ha realizado propiamente solo en el caso de María Chura Arcata vs. Banco de la Nación, en el que se declaró que la reducción del riesgo de incumplimiento de operaciones crediticias es un fin imperioso $(2017, \S 62)$. Tampoco queda claro el incremento en la rigurosidad del examen de necesidad toda vez que, por ejemplo, en el caso reseñado, el TC aceptó que la «denegación de cualquier posibilidad de acceder a un crédito a un grupo determinado de personas — en este caso, de los adultos mayores — permite reducir el riesgo de incumplimiento de pago» (§67), afirmación que ciertamente está afectada de sobreinclusión. Del mismo modo, en la jurisprudencia de la Corte IDH, fines tales como el interés superior del niño y la integridad personal se consideran en sí mismos fines imperiosos; sin embargo, la Corte IDH considera que la protección de estos intereses «se debe hacer a partir de la evaluación específica y concreta [...] y los riesgos reales y probados, y no especulativos o imaginarios que podrían generar» (Gonzalez Lluy, 2015, § 264). Así, por ejemplo, en Granier, la Corte concluyó que el Estado no había presentado suficientes pruebas que permitan concluir realmente cuán imperiosa era la finalidad estatal buscada por la medida diferenciadora $(\$ 230)$. Con relación al examen de necesidad, encontramos que este no es superado si la Corte halla «otras medidas menos lesivas»; sin embargo, estas «otras medidas» no se señalan explícitamente, por lo que no queda lo suficientemente justificada su relevancia para la decisión (I.V. vs. Bolivia, 2016, § 245).

Desde otro ángulo, Bedi argumenta que para predicar la coherencia, certeza y previsibilidad del examen de escrutinio estricto, debe delinearse claramente en qué casos se aplica este examen y la Corte Suprema de Estados Unidos estaría lejos de trazar una línea definida al respecto (2013, p. 70). Por ejemplo, para que se configure un criterio sospechoso en la jurisprudencia norteamericana, deben cumplirse requisitos tales como: una historia de discriminación profundamente arraigada, una desprotección en el marco del proceso político, una clasificación basada en un rasgo inmutable (sea porque no puede ser modificado por la voluntad humana o porque significaría una renuncia para el individuo de un aspecto esencial de su identidad), el carácter impropio de dicho rasgo como criterio de reparto, una situación de segregación geográfica que haga a determinado grupo minoritario visible ante otros (2013, p. 70; Frontiero vs. Richardson, 1973). No obstante, estos criterios son aplicados de manera impredecible, y algunos aplicados de modo por lo menos «curioso». En esa línea, Goldberg nota por ejemplo que, en el caso del requisito «historia de discriminación profundamente arraigada», la Corte Suprema la aplica respecto del criterio de raza (en el sentido de que en la historia innumerables sociedades han discriminado a grupos de personas en virtud de su raza) y no respecto de una clase particularmente afectada por una historia de diferenciación racial

¿SOSPECHAR

PARA IGUALAR?

UN ANÁLISIS

«ESTRICTO» DE

LA DOCTRINA DE

LAS CATEGORÍAS

SOSPECHOSAS

A PARTIR DE LA

JURISPRUDENCIA

DEL TRIBUNAL

CONSTITUCIONAL

PERUANO

Y LA CORTE

INTERAMERICANA

DE DERECHOS

HUMANOS

TO SUSPECT

IN ORDER

TO EQUATE?

$A$ «STRICT»

SCRUTINY OF

THE SUSPECT

CLASSIFICATIONS

DOCTRINE FROM

THE CASE LAW OF

THE PERUVIAN

CONSTITUTIONAL

COURT AND THE

INTER-AMERICAN

COURT OF HUMAN

RIGHTS 
injusta (2004, p. 508). Consecuentemente, en su ánimo de aplicar el examen estricto de modo «categórico», la Corte Suprema ha utilizado este examen para la evaluación de acciones positivas ${ }^{8}$ (ver sentencias de los casos Gratz vs. Bollinger, 2003; y Adarand Constructors, Inc. vs. Peña, 1995). En consecuencia, para Goldberg, los criterios propuestos por la Corte Suprema Norteamericana como determinantes para la calificación de una característica personal como sospechosa parecen no seguir un hilo lógico e incluso haber caído en el desuso, pues han transcurrido cuarenta años de jurisprudencia sin que la Corte identifique nuevos criterios sospechosos (y, por tanto, nuevas situaciones de discriminación) (2004, p. 504).

Esta crítica puede también extenderse a la aplicación del escrutinio estricto en la jurisprudencia de la Corte IDH, toda vez que no puede desprenderse de sus fallos que existan criterios uniformes para la identificación de criterios sospechosos. La Corte IDH, en Atala Riffo afirmó que la cláusula «otra condición social» del artículo 1.1 de la $\mathrm{CADH}$ debe interpretarse de la manera que más favorezca a la persona. Para ello, la Corte IDH se remite a diversos documentos de soft law y otros que expresarían una voluntad en el derecho internacional de prohibir categóricamente determinadas clases de discriminación (Pérez, 2016, p. 44) Sin embargo, esta afirmación adolece de extrema generalidad y deja a la Corte un alto grado de discrecionalidad para la identificación de nuevos criterios sospechosos. Así, por ejemplo, Ruiz Chiriboga ha criticado la metodología utilizada por la Corte IDH en la sentencia del caso Atala Riffo para la incorporación de la orientación sexual como criterio sospechoso. El autor cuestiona que la Corte no haya interpretado la frase «otra condición social» desde su sentido corriente y se haya limitado a recurrir el principio pro persona y citar asistemáticamente una serie de documentos de derecho internacional, sin distinguir si se trata de soft law; si se emitieron antes o después de sucedidos los hechos; y, si representan consensos de otros sistemas de protección, si se trata de pronunciamientos judiciales o informes (2012, p. 190). Si bien en I.V. vs. Bolivia la Corte ha propuesto que los nuevos criterios sospechosos sean asimilables a los ya listados en el artículo 1.1, por tratarse de rasgos identitarios permanentes, criterios irrelevantes de reparto y grupos tradicionalmente marginados, este estándar no ha sido aplicado ni siquiera en el mismo fallo, donde no se justificó por qué las personas refugiadas cumplirían con dicho requisito (2015,

8 Es preciso señalar que en la doctrina constitucional norteamericana existe un intenso debate en cuanto a la aplicación del examen de escrutinio estricto para acciones afirmativas. La Corte Suprema se ha mostrado proclive a aplicarlos. El juez Thomas, por ejemplo, considera que cualquier medida de paternalismo racial es perniciosa y marca a las minorías con un sello de inferioridad (Thomas, Opinión concurrente en la sentencia del caso Adarand Constructors, Inc. vs. Peña, 1995). Se han mostrado en contra de la aplicación de un examen estricto autores como Owen Fiss, Elizabeth Anderson y Sandra Fredman, para quienes las acciones positivas, más que una forma de discriminación injusta, son remedios contra la discriminación. Al respecto, ver Fredman (2011, pp. 232 y ss.) y Fiss (1976). 
$\S 240)$. En consecuencia, no puede aún predicarse la congruencia ni previsibilidad de la Corte IDH en esta materia.

Adicionalmente, no debe obviarse que el examen de escrutinio estricto supone una mayor limitación de la acción del legislador, de la administración y de la autonomía privada. La doctrina ha evidenciado que en muy pocas ocasiones una medida evaluada bajo escrutinio estricto ha sobrevivido a su aplicación; por ello, se ha afirmado que dicho examen es «estricto en la teoría, pero fatal en los hechos». Aquello puede notarse también en la jurisprudencia del TC y la Corte IDH, en la que, desde su aplicación, ninguna medida sometida al examen ha resultado ilesa. En ese sentido, coincidimos con Bernal Pulido, quien propone una aplicación excepcional del examen de escrutinio estricto, toda vez que mayores restricciones de la acción legislativa suponen, en simultáneo, una mayor intervención sobre el principio democrático (2010, p. 468). No obstante, nos alejamos de la posición del profesor colombiano cuando afirma que «el principal criterio para evaluar la determinación del tipo de escrutinio de igualdad, consiste en establecer si el trato diferente se funda en uno de los "criterios potencialmente discriminatorios", pero no todos los enunciados por la Corte Constitucional, sino sólo aquellos mencionados explícitamente por la Constitución, interpretados de manera restrictiva» (2010, p. 468). Consideramos que equiparar el reconocimiento explícito de criterios prohibidos por parte del legislador con la aplicación del test de escrutinio estricto no es siempre conveniente porque, como se ha mencionado antes, la labor verdaderamente importante reside en contextualizar dichos criterios; de no ser así, se imposibilitaría la identificación de nuevas situaciones de desventaja relativa que afectan a los integrantes de diferentes grupos sociales por el solo hecho de pertenecer a dichos grupos, limitando la acción correctora de la autoridad judicial. Más aún, nos preguntamos: ies ineludible la aplicación del examen de escrutinio estricto para resolver intervenciones graves sobre el derecho a la no discriminación? ¿Es el único medio plausible para identificar nuevas situaciones de desventaja relativa?

Por ejemplo, para Díaz de Valdés, el test de escrutinio ofrece una metodología que le permite al juez «ordenar y modelar su razonamiento» (2018, p. 195); sin embargo, no se trata de un efecto esencial, sino de «una consecuencia posible, de la utilización de las categorías sospechosas» (p. 198). Más aún, considera que la aplicación de un test distinto — de tipo «estricto»— «complica innecesariamente la labor del juez» (p. 196), toda vez que lo obliga a elaborar una especie de «dogmática» en torno a cada test, en la que identifique a qué tipo de categorías se aplica y la metodología propia de cada examen. Para el autor, lo importante es que se ofrezcan razones suficientes para convencer al juez de permitir dicha diferenciación, de modo que no resulta esencial una gradación

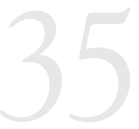

¿SOSPECHAR

PARA IGUALAR?

UN ANÁLISIS

«ESTRICTO» DE

LA DOCTRINA DE

LAS CATEGORÍAS

SOSPECHOSAS

A PARTIR DE LA

JURISPRUDENCIA

DEL TRIBUNAL

CONSTITUCIONAL

PERUANO

Y LA CORTE

INTERAMERICANA

DE DERECHOS

HUMANOS

TO SUSPECT

IN ORDER

TO EQUATE?

$A$ «STRICT»

SCRUTINY OF

THE SUSPECT

CLASSIFICATIONS

DOCTRINE FROM

THE CASE LAW OF

THE PERUVIAN

CONSTITUTIONAL

COURT AND THE

INTER-AMERICAN

COURT OF HUMAN

RIGHTS 
de diferentes tests, sino, antes bien, una elevación en la intensidad del estándar de convencimiento del juez (p. 195). Asimismo, considera en general irrelevante la inversión de la carga de la prueba en tanto en los juicios de discriminación es normalmente la víctima quien acredita la diferencia de trato, pero es normalmente el demandado quien la niega o, de aceptarla, la reputa razonable, para cuyos efectos «ofrece las razones de la distinción realizada, así como la eventual prueba asociada a ello» (p. 199).

En ese sentido, debe considerarse que si bien el principio de no discriminación exige la razonabilidad, no demanda necesariamente un escrutinio estricto. No obstante, autores como Gerards han reconocido que cierta variación en la intensidad del examen es indispensable para tomar en cuenta todos los intereses relevantes en juego en un caso (2018, p. 182), y otras como Howard han defendido un modelo de gradación de escrutinios en el que el examen más severo se aplica a criterios sospechosos fuertemente vinculados a los derechos fundamentales, la dignidad humana o la participación en el proceso político (2007, p. 469). Desde una postura disímil, autoras como Goldberg consideran que tal gradación no resulta necesaria una vez que se identifica el hilo conductor de los tres niveles de escrutinio y la diferencia específica que ofrece el escrutinio estricto respecto de los dos niveles inferiores. Para la autora, el propósito esencial de la equal protection clause no es otro que evitar que las leyes creen clases entre los ciudadanos sustentadas en argumentos no neutrales. Para identificar qué medidas violarían dicho principio, la autora propone un examen de tres pasos en el que se identifique, en primer lugar, si existe una explicación plausible, no arbitraria, de por qué un determinado grupo soporta la carga cuestionada en el contexto en cuestión; en segundo lugar, si la justificación ofrecida para atribuirle la carga a dicho grupo tiene una relación específica con el contexto de la clasificación; y, en tercer lugar, si la clasificación refleja desaprobación, desagrado o estereotipos contra el grupo de personas al que le impone la legislación (2004, p. 533). En el primer paso, se procuraría evidenciar qué razones ofrece el legislador para realizar la distinción; en el segundo, dilucidar si las razones ofrecidas tienen una conexión con la legislación (medio) propuesta; y, en el tercero, se consideraría si la clasificación esconde un propósito ilegítimo por basarse en un mero animus o estereotipo contra el grupo que distingue.

Por otro lado, Bedi ha sugerido una powers review en reemplazo del escrutinio estricto, la cual busca dilucidar no si la diferenciación afecta a un grupo o clase, sino la legitimidad de las razones ofrecidas por el legislador (2013, p. 90). En opinión del autor, el Estado podría presentar animadversión, prejuicios o estereotipos no necesariamente contra grupos de rasgos identitarios fuertes, sino incluso contra cualquier individuo, situación que es a todas luces arbitraria. La animadversión 
irracional contra una persona o grupo de personas es inconstitucional, no importa contra quién se dirija (p. 95). En ese sentido, sugiere que la Corte Suprema Norteamericana debe ser especialmente aguda al momento de examinar la finalidad de la medida diferenciadora a fin de identificar el verdadero propósito detrás de su emisión en sede legislativa, el que no siempre coincide con el propósito que se alega a posteriori como justificación para su defensa (p. 85). En suma, para Bedi, hay ciertas razones que son per se inconstitucionales; e integrarían este grupo políticas de tipo perfeccionista en lo moral, que no respetarían el principio de neutralidad estatal (p. 104). Para el autor, su enfoque tiene la ventaja de ser inclusivo y democrático, e impide que las mayorías caricaturicen a las minorías como «opresores» (p. 106).

Si bien, por la extensión y objetivos de este trabajo, no nos es posible ofrecer una fórmula alternativa al escrutinio estricto, consideramos que este no puede tenerse como la única vía para resolver injerencias graves sobre el derecho a la no discriminación. De una parte, no debería aplicarse el test estricto en el caso de todas las medidas diferenciadoras que involucren una categoría sospechosa explícitamente prohibida. Como vimos en acápites anteriores, esta aplicación mecanizada de la doctrina lleva a que se termine aplicando el control más exigente a medidas que tienen como propósito beneficiar a los integrantes de grupos desaventajados. De igual manera, consideramos que la misma determinación de la intensidad del examen de igualdad tampoco puede depender solamente del hecho de que la situación discriminatoria afecte a un grupo vulnerable. Como señala Díaz de Valdés, «en la práctica puede ser difícil administrar un sistema de categorías sospechosas con diferentes efectos según el grupo que se afecte» (2018, p. 194), ya que no siempre se conoce con certeza qué tipo de medidas son beneficiosas o perjudiciales para el grupo en cuestión. Incluso, puede confundirse al juzgador, toda vez que las categorías sospechosas describen no solo a un grupo social, sino a varios grupos, muchas veces todos desaventajados (en mayor o menor medida, como sucede, por ejemplo, con el caso de la categoría raza en el Perú, que incluye grupos tales como la población indígena y afrodescendiente).

Consideramos que la aplicación de la metodología del escrutinio estricto, como ha sido modelada por diversos tribunales, no es indispensable (Baker, 2008, p. 882); y sostenemos que una evaluación rigurosa no depende exclusivamente de la presencia de un criterio que pueda considerarse a priori sospechoso, sino antes bien de cuán arbitraria se percibe la medida a la que se ve sometido el justiciable que va en búsqueda de tutela jurisdiccional. La sospecha que la situación provoque en el juez puede resolverse, como propone Díaz de Valdés, exigiendo "grados diversos de convencimiento respecto de si existe una discriminación arbitraria o no» (2018, p. 195), los mismos que

¿SOSPECHAR

PARA IGUALAR?

UN ANÁLISIS

«ESTRICTO»DE

LA DOCTRINA DE

LAS CATEGORÍAS

SOSPECHOSAS

A PARTIR DE LA

JURISPRUDENCIA

DEL TRIBUNAL

CONSTITUCIONAL

PERUANO

Y LA CORTE

INTERAMERICANA

DE DERECHOS

HUMANOS

TO SUSPECT

IN ORDER

TO EQUATE?

$A$ «STRICT»

SCRUTINY OF

THE SUSPECT

CLASSIFICATIONS

DOCTRINE FROM

THE CASE LAW OF

THE PERUVIAN

CONSTITUTIONAL

COURT AND THE

INTER-AMERICAN

COURT OF HUMAN

RIGHTS 
deberán quedar evidenciados en el fallo judicial correspondiente. Para llegar a este grado de convencimiento, el juez puede recurrir al examen de razonabilidad o proporcionalidad (dependiendo de si el reclamo involucra o no el ejercicio de otro derecho fundamental). En suma, la metodología a aplicar puede ser diversa; no obstante, esta no sustituye al juez ni al juicio prudencial que este realiza para resolver la controversia en justicia.

\section{CONCLUSIÓN}

En este trabajo se ha evidenciado que existen varias similitudes entre la doctrina del TCy la de la Corte IDH sobre categorías sospechosas. Ambos tribunales reconocen como ratio del principio de no discriminación para la identificación de nuevos criterios sospechosos que estos se correspondan con la identificación de fenómenos de vulnerabilidad social de carácter grupal. Asimismo, ambos coinciden en la selección de la herramienta hermenéutica para evaluar una supuesta situación de discriminación: el examen de escrutinio estricto. No obstante, en la praxis, la Corte IDH ha sido más proclive a la identificación de nuevos criterios sospechosos, habiendo establecido como categorías sospechosas la orientación sexual, el origen étnico, la condición de VIH positivo, la línea editorial de un medio de comunicación, la pobreza, la discapacidad, la condición de adulto mayor y la condición de migrante; mientras que el TC solo lo ha hecho respecto de la condición de discapacidad y la condición de adulto mayor.

Igualmente, se ha podido apreciar que ninguno de los tribunales objeto de estudio de este trabajo ha valorado las implicancias del viraje en su comprensión del principio de no discriminación, la que se acerca más a una comprensión de la igualdad como «no sometimiento» o como «reconocimiento» de grupos vulnerables. De acuerdo a un sector de la doctrina, al centrar la injusticia de un acto discriminatorio en la desventaja que ocasiona a los miembros de un determinado grupo social, este enfoque tiene el grave costo de minimizar las consecuencias de dicho acto para el individuo que lo ha padecido. Adicionalmente, se ha evidenciado que ninguno de los tribunales ha justificado la aplicación de un examen de escrutinio estricto para la evaluación de medidas diferenciadoras sobre la base de criterios sospechosos, ni ha adecuado para este examen una metodología que permita asegurar mayores niveles de rigurosidad y objetividad al momento de resolver una controversia de no discriminación.

Consideramos que hay dos posibilidades al alcance de las manos de los tribunales para hacerle frente a las objeciones que la aplicación de la doctrina de las categorías sospechosas supone desde los enfoques arriba mencionados. En primer lugar, contextualizar la identificación 
de categorías o criterios sospechosos sobre la base de un examen de las condiciones históricas, sociales y políticas de la persona afectada por la situación aparentemente discriminatoria, así como de la situación particular de la víctima en el caso concreto; es decir, identificar «situaciones sospechosas» en concreto, en lugar de «categorías sospechosas» a priori. En segundo lugar, ninguno de los tribunales debería considerar indispensable la aplicación de un examen de escrutinio estricto (bajo la fórmula propuesta por diversas jurisdicciones extranjeras). Los métodos a aplicar para resolver una controversia de no discriminUnación pueden ser diversos, pues la esencia de la evaluación reside en exigir de parte de los jueces un alto nivel de convencimiento respecto a la razonabilidad de la medida diferenciadora; por el contrario, de no llegar estos a dicho techo, se deberá invalidar la medida.

\section{REFERENCIAS}

Alexander, L. (1992). What Makes Wrongful Discrimination Wrong? Biases, Preference, Stereotypes, and Proxies. University of Pennsylvania Law Review, 141(1), 149-219. doi: https://doi.org/10.2307/3312397

Arnardóttir, O. M. (2017). Vulnerability under Article 14 of the European Convention on Human Rights. Innovation or Business as Usual? Oslo Law Review, 3(4), artículo 3. doi: https://doi.org/10.18261/issn.2387-3299-2017-03-03

Baker, A. (2008). Proportional, Not Strict, Scrutiny: Against a U.S. "Suspect Classifications" Model under Article 14 ECHR in the U.K. American Journal of Comparative Law, 56(4), 847-894. doi: https://doi.org/10.5131/ajcl.2007.0030

Barrere, M. A., \& Morondo, D. (2011). Subordinación y discriminación interseccional: elementos para una teoría del derecho antidiscriminatorio. Anales de la cátedra Francisco Suárez, 45, 15-42. Recuperado de: http://revistaseug.ugr.es/ index.php/acfs/article/view/523

Barrere, M. A. (2016). Martha A. Fineman y la igualdad jurídica: iVulnerabilidad vs. Subordiscriminación? Cuadernos Electrónicos de Filosofía del Derecho, (34), 17-34. doi: https://doi.org/10.7203/cefd.34.8927

Bayefsky, A. (1990). The Principle of Equality and Non-discrimination in International Law. Human Rights Law Joumal, 11 (1-2), 1-34.

Bedi, S. (2013). Beyond Race, Sex and Sexual Orientation: Legal Equality without Identity. Cambridge: Cambridge University Press. doi: https://doi.org/10.1017/ CBO9781139087643

Bernal, C. (2010). El juicio de igualdad en la Corte Constitucional Colombiana. En D. Caicedo Tapia \& A. Porras Velasco (eds.), Igualdad y no discriminación. El reto de la diversidad (pp. 451-482). Quito: Ministerio de Justicia, Derechos Humanos y Cultos de Ecuador. Recuperado de: https://estudogeral.sib.uc.pt/ bitstream/10316/41728/1/Desigualdad\%2C\%20exclusi\%C3\%B3n\%20y\%20 globalizaci\%C3\%B3n.pdf

¿SOSPECHAR

PARA IGUALAR?

UN ANÁLISIS

«ESTRICTO»DE

LA DOCTRINA DE

LAS CATEGORÍAS

SOSPECHOSAS

A PARTIR DE LA

JURISPRUDENCIA

DEL TRIBUNAL

CONSTITUCIONAL

PERUANO

Y LA CORTE

INTERAMERICANA

DE DERECHOS

HUMANOS

TO SUSPECT

IN ORDER

TO EQUATE?

$A$ «STRICT»

SCRUTINY OF

THE SUSPECT

CLASSIFICATIONS

DOCTRINE FROM

THE CASE LAW OF

THE PERUVIAN

CONSTITUTIONAL

COURT AND THE

INTER-AMERICAN

COURT OF HUMAN

RIGHTS 
Bilbao Ubillús, J. M., \& Rey Martínez, F. (2003). El principio constitucional de igualdad en la jurisprudencia constitucional española. En M. Carbonell (comp.), El principio de igualdad constitucional. México: Comisión Nacional de Derechos Humanos.

Biscardi, M. C., \& Garibotti, S. (2009). Más allá de Carolene Products. Revista Jurídica de la Universidad de Palermo, 10(1), 125-156. Recuperado de https://www. palermo.edu/derecho/revista_juridica/pub-10/10Jurica05.pdf

Blum, L. (2013). Racial and other Asymmetries. A Problem for the Protected Categories Framework for Anti-Discrimination Thought. En S. Moureau \& D. Heller (eds.), Philosophical Foundations of Discrimination Law (pp. 182-199). Oxford. Oxford University Press. doi: https://doi.org/10.1093/acprof :oso/9780199664313.003.0010

Choudry, S. (2000). Distribution vs. Recognition: The Case of Antidiscrimination Laws. George Mason Law Review, 9(1), 145-178. Recuperado de: https://papers. ssrn.com/sol3/papers.cfm?abstract_id=1624085

Clérico, L. (2017). Derecho constitucional y derechos humanos: haciendo manejable el análisis de estereotipos. Revista Derechos en Acción, 2(5), 207-241. doi: https://doi.org/10.24215/25251678e094

Clérico, L. (2012). Impacto del caso Atala: posibilidades y desafíos. En A. Von Bogdandy, F. Piovesan \& M. Morales-Antoniazzi (coords.), Igualdad y orientación sexual. El caso Atala de la Corte Interamericana de Derechos Humanos y su potencial (pp. 27-57). México: Porrúa.

Clérico, L., \& Aldao, M. (2011). Nuevas miradas de la igualdad en la jurisprudencia de la Corte Interamericana de Derechos Humanos: la igualdad como redistribución y reconocimiento. Lecciones y Ensayos, (89), 141-179. Recuperado de: http://www.derecho.uba.ar/publicaciones/lye/revistas/89/clericolaura-y-aldao-martin-nuevas-miradas-de-la-igualdad.pdf

Díaz de Valdés, J. M. (2018). Las categorías sospechosas en el Derecho Chileno. Revista de Derecho de la Pontificia Universidad Católica de Valparaíso, (50), 189-218. doi: http://dx.doi.org/10.4067/S0718-68512018000100189

Didier, M. M. (2012). El principio de igualdad en las normas jurídicas. Buenos Aires: Marcial Pons.

Dulitzky, A. (2010). El principio de igualdad y o discriminación. Claroscuros de la jurisprudencia interamericana. En D. Caicedo \& A. Porras (eds.), Igualdad y no discriminación. El reto de la diversidad (pp. 575-612). Quito: Ministerio de Justicia, Derechos Humanos y Cultos de Ecuador. doi: https://doi.org/10.5354/07182058.2007.13452

Fernández, E. (2003). Igualdad y derechos humanos. Madrid: Tecnos.

Fineman, M. A. (2012) Beyond Identities: The Limits of an Antidiscrimination Approach to Equality. Boston University Law Review, 92(6), 1713-1779. Recuperado de: https://papers.ssrn.com/sol3/papers.cfm?abstract_id=2192316 
Fiss, O. (1976). Groups and the equal protection clause. Philosophy and Public Affairs, 5(2), 107-177. Recuperado de: https://philpapers.org/rec/FISGAT

Fredman, S. (2016). Substantive equality revisited. International Journal of Constitutional Law, 14(3), 712-738. doi: https://doi.org/10.1093/icon/mow043

Gerards, Janneke (2004). Intensity of Judicial Review in Equal Treatment Cases. Netherlands International Law Review, 51 (2), 135-183. doi: https://doi.org/10.1017/ s0165070x04001354

Gerards, Janneke (2013). The Discrimination Grounds of Article 14 of the European Convention on Human Rights. Human Rights Law Review, 13(1), 99-124. doi: https://doi.org/10.1093/hrlr/ngs044

Giardelli, L., Toller, F., \& Cianciardo, J. (2009). Los estándares para juzgar normas que realizan distinciones. Paralelismo entre la doctrina de la Corte Suprema estadounidense y el Sistema Interamericano de derechos humanos sobre el Derecho a la Igualdad. En E. Ferrer Mac-Gregor \& A. Zaldívar Lelo de Larrea (eds.), La ciencia del Derecho Procesal Constitucional. Estudios en homenaje a Héctor Fix-Zamudio en sus cincuenta años como investigador del Derecho (IV, pp. 301-343). Santiago de Chile: Centro de Estudios Constitucionales de Chile, Instituto de Investigaciones Jurídicas de la UNAM, Librotecnia.

Goldberg, S. (2004). Equality Without Tiers. Southerm Califormia Law Review, 77(3), 481-583. Recuperado de: https://southerncalifornialawreview.com/2004/03/05/ equality-without-tiers-article-by-suzanne-b-goldberg/

Gonzalez Le Saux, M., \& Parra, O. (2008). Concepciones y cláusulas de igualdad en la Jurisprudencia de la Corte Interamericana. A propósito del caso Apitz. Revista IIDH, 47(1), 128-164. Recuperado de: http://www.corteidh.or.cr/tablas/ r23826.pdf

Howard, E. (2007). The Case for a Considered Hierarchy of Discrimination Grounds in EU Law. Maastricht Journal of European and Comparative Law, 13(4), 445-470. doi: https://doi.org/10.1177/1023263x0601300404

Hellman, D. (2008). When is Discrimination Wrong? Cambridge, Massachusetts: Harvard University Press.

Iyer, N. (1993). Categorical denials: Equality Rights and the shaping of social identity. Queen's Law Journal, 19(1), 179-207.

Khaitan, T. (2015). A Theory of Discrimination Law. Oxford: Oxford University Press.

Minow, M. (1997). Not Only for Myself: Identity, Politics and the Law. Nueva York: New Press.

Pérez, E. (2016). La igualdad y no discriminación en el derecho interamericano de los derechos humanos. México: Comisión Nacional de los Derechos Humanos. Recuperado de: http://appweb.cndh.org.mx/biblioteca/archivos/pdfs/fas-CSIDHIgualdad-No-Discriminacion_1.pdf

¿SOSPECHAR

PARA IGUALAR?

UN ANÁLISIS

«ESTRICTO» DE

LA DOCTRINA DE

LAS CATEGORÍAS

SOSPECHOSAS

A PARTIR DE LA

JURISPRUDENCIA

DEL TRIBUNAL

CONSTITUCIONAL

PERUANO

Y LA CORTE

INTERAMERICANA

DE DERECHOS

HUMANOS

TO SUSPECT

IN ORDER

TO EQUATE?

$A$ «STRICT»

SCRUTINY OF

THE SUSPECT

CLASSIFICATIONS

DOCTRINE FROM

THE CASE LAW OF

THE PERUVIAN

CONSTITUTIONAL

COURT AND THE

INTER-AMERICAN

COURT OF HUMAN

RIGHTS 
Pérez, K. (2005). Principio de igualdad. Alcances y perspectivas. México: Universidad Nacional Autónoma de México.

Peroni, L., \& Timmer, A. (2013). Vulnerable groups: The promise of an emerging concept in European Human Rights Convention Law. International Journal of Constitutional Law, 11 (4), 1056-1085. doi: https://doi.org/10.1093/icon/mot042

Rivers, J. (2006). Proportionality and variable intensity of review. The Cambridge Law Journal, 65(1), 174-207. doi: https://doi.org/10.1017/S0008197306007082

Ruiz Chiriboga, O. (2012). Cláusulas autónomas, subordinadas e incorporadas de igualdad y no discriminación en el Sistema Interamericano. En J. A. Mejía (coord.), Los derechos humanos en las sentencias de la Corte Interamericana sobre Honduras (pp. 175-218). Tegucigalpa: Casa San Ignacio.

Saba, R. (2009). Igualdad, clases y clasificaciones. ¿Qué es lo sospechoso de las categorías sospechosas? En R. Gargarella (ed.), Teoría y crítica del Derecho Constitucional (II, pp. 695-742). Buenos Aires: Abeledo Perrot.

Saldivia, L. (2011). Categorías sospechosas, flexibles y contextuadas. En R. Gargarella (comp.), La Constitución en 2020: 48 propuestas para una sociedad más ignalitaria (pp. 37-44). Buenos Aires: Siglo XXI.

Young, I. M. (1990). Justice and the Politics of Difference. Nueva Jersey: Princeton University Press.

\section{Jurisprudencia, normativa y otros documentos legales}

Acción de inconstitucionalidad de 2015. 8/2014.

Adarand Constructors Inc. vs. Peña, 515 U.S. 200 (Corte Suprema [Estados Unidos de América], 1995).

Amparo Directo en Revisión. 1387/2012 (Corte Suprema [Estados Unidos Mexicanos], 2012).

Amparo en Revisión. 615/2013 (Corte Suprema [Estados Unidos Mexicanos], 2013).

Andrea Celeste Álvarez Villanueva vs. Ministerio de Defensa. Acción de amparo. Expediente $N^{\circ}$ 1423-2013-PA (TC [Perú], 9 de diciembre de 2015). Recuperado de: http://www.tc.gob.pe/jurisprudencia/2016/01423-2013-AA.pdf

Artavia Murillo y otros vs. Costa Rica. Caso contencioso. Serie C N 318 (Corte IDH, 28 de noviembre de 2012). Recuperado de: http://www.corteidh.or.cr/docs/ casos/articulos/seriec_257_esp.pdf

Arturo Castillo Chirinos us. Jurado Nacional de Elecciones. Acción de amparo. Expediente $\mathrm{N}^{\circ}$ 2730-2006-PA (TC [Perú], 21 de julio de 2006). Recuperado de: https:/tc.gob.pe/jurisprudencia/2006/02730-2006-AA.pdf

Atala Riffo y niñas vs. Chile. Caso contencioso. Serie C N 239 (Corte IDH, 12 de febrero de 2012). Recuperado de: http://www.corteidh.or.cr/docs/casos/articulos/ seriec_239_esp.pdf 
Cinco mil setenta y siete ciudadanos vs. Congreso de la República. Acción de inconstitucionalidad. Expediente $\mathrm{N}^{\circ}$ 018-2003-AI (TC [Perú], 26 de abril de 2004). Recuperado de: https://tc.gob.pe/jurisprudencia/2004/00018-2003-AI. html

Colegio de Abogados del Cono Norte de Lima vs. Congreso de la República. Acción de inconstitucionalidad. Expediente $N^{\circ}$ 045-2004-PI (TC [Perú], 29 de octubre de 2005). Recuperado de: http://www.tc.gob.pe/jurisprudencia/2006/00045-2004AI.pdf

Controversia Constitucional. 32/2009 (Corte Suprema [Estados Unidos de América], 2009).

¿SOSPECHAR

PARA IGUALAR?

UN ANÁLISIS

«ESTRICTO»DE

LA DOCTRINA DE

LAS CATEGORÍAS

SOSPECHOSAS

Fiscal de la Nación vs. Congreso de la República. Acción de inconstitucionalidad. Expediente $N^{\circ}$ 0004-2006-PI (TC [Perú], 29 de marzo de 2006). Recuperado de: https://tc.gob.pe/jurisprudencia/2006/00004-2006-AI.pdf

Frontiero vs. Richardson. 411 U.S. 677 (Corte Suprema [Estados Unidos de América], 1973).

Furlán y familiares vs. Argentina. Caso contencioso. Serie C N 246 (Corte IDH, 31 de agosto de 2012). Recuperado de: http://www.corteidh.or.cr/docs/casos/ articulos/seriec_246_esp.pdf

Gobierno Regional de San Martín vs. Congreso de la República. Acción de inconstitucionalidad. Expediente $\mathrm{N}^{\circ}$ 00047-2004-AI (TC [Perú], 24 de abril de 2006). Recuperado de: https://www.tc.gob.pe/jurisprudencia/2006/00047-2004AI.html

González Lhyy vs. Ecuador. Caso contencioso. Serie C N² 298 (Corte IDH, 1 de setiembre de 2015). Recuperado de: http://www.corteidh.or.cr/docs/casos/ articulos/seriec_298_esp.pdf

Granier y otros (Radio Caracas Televisión) vs. Venezuela. Caso contencioso. Serie C N 293 (Corte IDH, 22 de junio de 2015). Recuperado de: http://www.corteidh. or.cr/docs/casos/articulos/seriec_293_esp.pdf

Gratz vs. Bollinger. 539 U.S. 244 (Corte Suprema [Estados Unidos de América], 2003).

Gregory vs. Aschroft. 501 U.S. 452 (Corte Suprema [Estados Unidos de América], 1991).

Hooft, Pedro Comelio Federico vs. Buenos Aires, Provincia de s/ acción declarativa de inconstitucionalidad. H.172.XXXV (Corte Suprema [Argentina], 2004).

I. V. vs. Bolivia. Caso contencioso. Serie C N 329 (Corte IDH, 30 de noviembre de 2016). Recuperado de: https://www.corteidh.or.cr/docs/casos/articulos/ seriec_329_esp.pdf

Jane Margarita Cósar Camacho y otros vs. Supermercados Peruanos S.A. Plaza Vea. Acción de amparo. Expediente $N^{\circ}$ 02437-2013-PA (TC [Perú], 16 de abril de

A PARTIR DE LA

JURISPRUDENCIA

DEL TRIBUNAL

CONSTITUCIONAL

PERUANO

Y LA CORTE

INTERAMERICANA

DE DERECHOS

HUMANOS

TO SUSPECT

IN ORDER

TO EQUATE?

$A$ «STRICT»

SCRUTINY OF

THE SUSPECT

CLASSIFICATIONS

DOCTRINE FROM

THE CASE LAW OF

THE PERUVIAN

CONSTITUTIONAL

COURT AND THE

INTER-AMERICAN

COURT OF HUMAN

RIGHTS 
2014). Recuperado de: http://www.tc.gob.pe/jurisprudencia/2014/02437-2013AA.pdf

La colegiación obligatoria de periodistas. Opinión consultiva OC 4/84. Serie $\mathrm{A} \mathrm{N}^{\circ} 4$ (Corte IDH, 19 de enero de 1984).

María Chura Arcata vs. Banco de la Nación. Acción de amparo. Expediente $\mathrm{N}^{\circ}$ 05157-2014-PA (TC [Perú], 4 de abril de 2017). Recuperado de: http://www. tc.gob.pe/jurisprudencia/2017/05157-2014-AA.pdf

Massachussets Board of Retirement vs. Murgia. 427 U.S. 307 (Corte Suprema [Estados Unidos de América], 1976).

Miguel Alejandro Cadillo Palomino vs. Ministerio de Trabajo y Promoción del Empleo. Acción de amparo. Expediente $\mathrm{N}^{\circ}$ 2317-2010-AA (TC [Perú], 3 de setiembre de 2010). Recuperado de: http://www.tc.gob.pe/jurisprudencia/2010/02317-2010AA.html

Nadege Dorzema y otros vs. República Dominicana. Caso contencioso. Serie C No 251 (Corte IDH, 24 de octubre de 2012). Recuperado de: http://www.corteidh. or.cr/docs/casos/articulos/seriec_251_esp.pdf

Norín Catrimán y otros vs. Chile. Caso contencioso. Serie C N 279 (Corte IDH, 29 de mayo de 2014). Recuperado de: http://www.corteidh.or.cr/docs/casos/ articulos/seriec_279_esp.pdf

Pedro Andrés Lizana Puelles vs. Jurado Nacional de Elecciones. Acción de amparo. Expediente N ${ }^{\circ}$ 5854-2005-AA (TC [Perú], 8 de noviembre de 2015). Recuperado de: http://www.tc.gob.pe/jurisprudencia/2005/05854-2005-AA.pdf

Poblete Vilches y otros us. Chile. Caso contencioso. Serie CN 349 (Corte IDH, 8 de marzo de 2018). Recuperado de: http://www.corteidh.or.cr/docs/casos/articulos/ seriec_349_esp.pdf

Sentencia C-093 (Corte Constitucional [Colombia], 2001).

Sentencia C-671 (Corte Constitucional [Colombia], 2001).

Sentencia N 080-13-SEP-CC (Corte Constitucional [Colombia], 2013).

Sentencia N²92-16-SEP-CC (Corte Constitucional [Colombia], 2016).

Sentencia N ${ }^{\circ}$ 057-17-SEP-CC (Corte Constitucional [Colombia], 2017).

Sentencia N 004-18-SE.P-CC (Corte Constitucional [Ecuador], 2018).

T-376 (Corte Constitucional [Colombia], 2013).

Trabajadores de la Hacienda Brasil Verde vs. Brasil. Caso contencioso. Serie C N 318 (Corte IDH, 20 de octubre de 2016). Recuperado de: http://www.corteidh. or.cr/docs/casos/articulos/seriec_318_esp.pdf

Trabajadores de la Hacienda Brasil Verde vs. Brasil. Voto razonado del Juez Eduardo Ferrer Mac-Gregor. Serie C N 318 (Corte IDH, 20 de octubre de 2016). Recuperado de: http://www.corteidh.or.cr/docs/casos/articulos/seriec_318_esp. pdf 
Ximenes Lopes vs. Brasil. Caso contencioso. Serie C No 149 (Corte IDH, 4 de julio de 2006). Recuperado de: http://www.corteidh.or.cr/docs/casos/articulos/ Seriec_149_esp.pdf

Recibido: 18/01/2019
Aprobado: 20/05/2019
¿SOSPECHAR

PARA IGUALAR?

UN ANÁLISIS

«ESTRICTO» DE

LA DOCTRINA DE

LAS CATEGORÍAS

SOSPECHOSAS

A PARTIR DE LA

JURISPRUDENCIA

DEL TRIBUNAL

CONSTITUCIONAL

PERUANO

Y LA CORTE

INTERAMERICANA

DE DERECHOS

HUMANOS

TO SUSPECT

IN ORDER

TO EQUATE?

$\mathrm{A}$ «STRICT»

SCRUTINY OF

THE SUSPECT

CLASSIFICATIONS

DOCTRINE FROM

THE CASE LAW OF

THE PERUVIAN

CONSTITUTIONAL

COURT AND THE

INTER-AMERICAN

COURT OF HUMAN

RIGHTS 